Physics

AEC Research and Development Report

\title{
RESONANCE INTEGRALS \\ AND SELF-SHIELDING FACTORS FOR DETECTOR FOILS
}

by

N. P. Baumann

Experimental Physics Division

January 1963

E. I. du Pont de Nemours \& Co.

Savannah River Laboratory

Aiken, South Carolina 


\section{DISCLAIMER}

This report was prepared as an account of work sponsored by an agency of the United States Government. Neither the United States Government nor any agency Thereof, nor any of their employees, makes any warranty, express or implied, or assumes any legal liability or responsibility for the accuracy, completeness, or usefulness of any information, apparatus, product, or process disclosed, or represents that its use would not infringe privately owned rights. Reference herein to any specific commercial product, process, or service by trade name, trademark, manufacturer, or otherwise does not necessarily constitute or imply its endorsement, recommendation, or favoring by the United States Government or any agency thereof. The views and opinions of authors expressed herein do not necessarily state or reflect those of the United States Government or any agency thereof. 


\section{DISCLAIMER}

Portions of this document may be illegible in electronic image products. Images are produced from the best available original document. 
This report was prepared as an account of Government sponsored work. Neither the United States, nor the Commission, nor any person acting on behalf of the Commission:

A. Makes any warranty or representation, expressed or implied, with respect to the accuracy, completeness, or usefulness of the information contained in this report, or that the use of any information, apparatus, method, or process disclosed in this report may not infringe privately owned rights; or

B. Assumes any liabilities with respect to the use of, or for damages resulting from the use of any information, apparatus, method, or process disclosed in this report.

As used in the above, "person acting on behalf of the Commission" includes any employee or contractor of the Commission, or employee of such contractor, to the extent that such employee or contractor of the Commission, or employee of such contractor prepares, disseminates, or provides access to, any information pursuant to hils employment or contract with the Commission, or his employment with such contractor.

Printed in USA. Price $\$ 1.25$

Available from the Office of Technical Services

U. S. Department of Commerce

Washington 25, D. C. 
PHYSICS

(TID-4500, 18th Ed.)

\title{
RESONANCE INTEGRALS AND SELF-SHIELDING FACTORS FOR DETECTOR FOILS
}

\author{
by \\ Norman P. Baumann \\ January 1963
}

E. I. du Pont de Nemours \& Co.

Explosives Department - Atomic Energy Division

Technical Division - Savarmah River Laboratory

Aiken, South Carolina

Contract $\operatorname{AT}(07-2)-1$ with the

United States Atomic Energy Commission

Approved by

J. L. Cranda 11, Research Manager

Experimental Physics Division 


\begin{abstract}
Eflective activation resonance integrals for thin and thick folls in an isotropic neutron flux were measured by a cadmium ratio method. Gold was used as a standard. Values obtalned for dilute resonance integrals in barns, not including $1 / \mathrm{v}$ capture, were: $\mathrm{Au}^{197}, 1390 \pm 40$ (Reference); $\mathrm{U}^{238}$ capture, $280 \pm 10 ; \mathrm{Cu}^{63}, 3.17 \pm 0.18 ; \mathrm{Cu}^{65}, 1.39 \pm 0.22$; $\mathrm{Mo}^{98}, 9.9 \pm 1.1 ; \mathrm{Mo}^{100}, 4.06 \pm 0.23 ; \mathrm{w}^{186}, 476 \pm 50$; and $\mathrm{Na}^{23}, 0.075 \pm 0.010$. Dilute resonance integrals including $1 / \mathrm{v}$ capture above $0.60 \mathrm{ev}$ were: $\mathrm{U}^{235}$ fission, $263 \pm 9$ and $\operatorname{In}^{115}, 3200 \pm 100$. These resonance integrals and the measured resonance flux selfshielding factors were generally in good agreement with calculations. However, the two 1sotopes of molybdenum appearen to have major contributions to their resonance integrals from nontabulated resonances.
\end{abstract}




\section{CONTENTS}

$\underline{\text { Page }}$

List of Tables . . . 4

List of Figures 5

Introduction $\quad \ddots \quad 6$

Summary 6

Discussion 8

Theuietical 8

Definition of Resonance Integral 8

Method of Measurement 9

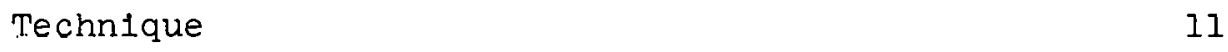

Method (Experimental) 11

Gold Calibration 13

Effective Resonance Integrals 16

$\mathrm{Cu}^{63}$ and $\mathrm{Cu}^{65} \quad 16$

$\mathrm{Mo}^{98}$ and $\mathrm{Mo}^{100} 19$

$\mathrm{Na}^{23} \cdot 23$

$\mathrm{U}^{235}$ Fission $\quad 25$

$\mathrm{U}^{238}$ Capture $\quad 27$

$\operatorname{In}^{215} \quad 31$

$\mathrm{W}^{186} \quad 34$

Noutron spectrum in the SP 35

Appendix A - Calculation of Flux Depression Factors 3'7

Appendix B - Effective Cadmium Cutoff Energies 43

Appendix C - Method for Determining Cadmium Ratios of Short-Iived Isotopes 44

Appendix D - Determination of the Effective Resonance Energy for $\mathrm{Mo}^{98}$ and Molon 46

Bibliography 49 


\section{LIST OF TABLES}

Table

$\underline{\text { Page }}$

I Dilute Resonance Activation Integrals for

Various Detector Materials

II. Computed Resonance and Thermal Depression

Factors for Gold Foll Activations in an

Isotropic Flux in a Cavity

III Measured Cadmium Ratios and Resonance Integrals for $\mathrm{Cu}^{63}$ and $\mathrm{Cu}^{65}$

IV Measured Carminn Rat1oo and Resunance Integrals for Mo 98 and Mo 100

$\mathrm{V}$ Resonance Integrals for $\mathrm{Mn}^{98}$ and $\mathrm{MO}^{100}$. ' $\mathrm{C}^{10}$

VI Measured Cadmium Ratios and Resonance Integrals f'or $\mathrm{Na}^{23}$

VII Measured Cadmium Ratios and Resonance Integrals for $U^{238}$ Capture

VIII Comparison of the Thermal and Resonance Activation. Cross Sections for the 13-Second and 54-Minute Activities of $\operatorname{In}^{116}$

IX Computed Resonance and Thermal Depression Factors for In ${ }^{15}$ Activations in an Isotropic Flux in a Cavity 


\section{LIST OF FIGURES}

F1gure

$\underline{\text { Page }}$

$1 \quad$ Fo1l Irradiation Apparatus

12

- 2 Thickness Corrections for Cadmium Ratios of $\mathrm{Au}^{197}$ Foils (Isotropic Flux in Cavity)

3. Effective Resonance Integral for $\mathrm{Cu}^{63}$ and $\mathrm{Cu}^{65}$ as a Function of Foll Thickness (Isotropic Flux in Cavity)

4 Effective Resonance Integral for $\mathrm{MO}^{30}$ and $\mathrm{MO}^{\mathrm{Inn}}$ as a Function of Foll Thickness (Isotropic Flux in Cavity)

5 Effective Resonance Capture Integral for $U^{238}$ as a Function of Foll Thickness (Isotropic Flux in Cavity)

6 Thickness Corrections for Cadmium Ratios of In ${ }^{15}$ and $W^{186}$ Fo1ls (Isotrop1c Flux in Cavity) 34

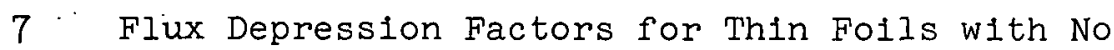
Doppler Broadening

8 Resonance Flux Depression Factors for Thick Folls with No Doppler Broadening

9 Resonance Flux Depression Factors for Thin

Folls with Doppler Broadening Included

10 Resonance Flux Depression Factors for Thick

Folls with Doppler Broadening Included

1.1 Effective Cadmiun Cutoff Energies for Thin I/V Detector Folls

12 Shielding of Resonance Detector Foils by Boron Covers 


\section{RESONANCE INTEGRALS AND SELF-SHIELDING FACTORS FOR DETECTOR FOILS}

\section{INTRODUCTION}

Resonance detector folls are an essential tool for reactor physics measurements. However, their usefulness depends on the precision with which their resonance parameters are known. Such parameters include the resonance energy, resonance width, resonance integral, and self-shlelding factors. The resonance energies and reaction widths are generally avallable(1) from neutron cross section measurements for the energy regions in which resonances for various isotopes can be resolved. Reasonably complete summaries of resonance integrals have also boon publislied $(F, i)$, hit. resonanoc integid. medsurements are sublest. tin sizable crrors aldsling from self-shielding effects, non-1/E spectra, and other sources.

The present experiments were undertaken to obtain precise measurements of. resonance integrals for some of the more commonly used resonance detectors. The oxperiments were designed to give the dilute, or unshielded, resonance integrals as well as to give the variation of the effective resonance integral with foll thickness over commonly used thickness ranges.

\section{SUMMARY}

Measurements and calculations of resonance integrals and flux depression factors have been made for foll activations in $\mathrm{U}^{235}, \mathrm{U}^{238}, \mathrm{~W}^{186}, \mathrm{In}^{115}, \mathrm{Na}^{23}, \mathrm{Cu}^{63}, \mathrm{Cu}^{65}, \mathrm{MO}^{98}$, and $\mathrm{MO}^{100}$. Mcasuremenl's were made by the "cadmium ratio" method, with $\mathrm{Au}^{197}$ as the reference material. The infinite dilution activation integrals are given in Table $I$.

The resonance flux depression factors were calculated as a function of foil thickness for those materials whose resonance parameters were avallable. The calculations Included the effect of Doppler broadening but neglected the effect of resonance scattering. The agreement with experiment was extremely good for $\mathrm{U}^{238}$, $\mathrm{In}^{115}, \mathrm{nu}^{197}, \mathrm{Mu}^{98}$, and Molon. A marked disparity was observed for $\mathrm{W}^{186}$, which is qualitatively explained by the very large scattering component of the tungsten resonance. Computations of self-shielding effects for the copper isotopes were not made because sufficient data for the resonances were not avallable. The resonance selfshielding for $\mathrm{Na}^{23}$ and $\mathrm{U}^{235}$ was negligible for the fo1l thicknesses used. 
Speclal methods were devised to treat the special problems imposed by the various foll materials. For $\mathrm{W}^{186}$, a resonance in $\mathrm{Cd}^{13}$ overlaps the 18.8-ev resonance. Measurements of the resultant shlelding were made by comparing cadmium ratios of the tungsten activity with similar boron ratios. The boron measurements gave resonance integrals for $\mathrm{W}^{186}$ about $24 \%$ greater than those derived from the cadmium measurements. For In $^{115}$, neutron capture leads to two modes of decay; one with a 54-minute half-11fe, the other with a 13-second halfI1fe. The branching ratio of the two modes for thermal neutron capture has been published $(1)$, but a report of such measurements for eplcadmium captures could not be found. Th1s determination was made in the present experiment by comparison of cadmium ratios for the twu activities. A special double counter method was used to obtain precise activity ratios for the 13-second activity. The measured resonance integral of $\mathrm{Mo}^{98}$ greatly exceeded that calculated from the parameters of the single tabulated resonance. Measurements were undertaken with successive thickness of boron shielding to try to locate the difficulty. These experiments showed that a major portion of the $\mathrm{Mo}^{98}$ resonance integral originated at an energy in the vicinity of $100 \mathrm{ev}$, well below the tabulated resonance of $480 \mathrm{ev}$. They also 1ndicated that Mo 100 has significant resonance integral contributions at energies much higher than the tabulated resonance at $367 \mathrm{ev}$. Unt1l the unknown resonances are 1dentified, ne1ther of these molybdenum 1sotopes appears useful as a resonance detector.

\section{TABLE I}

Dilute Resonance Activation Integrals for Various Metiector Materials

\begin{tabular}{|c|c|c|c|}
\hline \multicolumn{2}{|c|}{ Isotone } & $\mathrm{g} \sigma_{\mathrm{th}}$, barns $(\mathrm{a})$ & $\underline{R I^{R e s}}$, varns $(b)$ \\
\hline $\mathrm{Au}^{187}$ & (Reference) & 99.4 & $1490 \pm 40$ \\
\hline & $\mathrm{Na}^{23}$ & 0.52 & $0.075 \pm 0.010$ \\
\hline & $\mathrm{Cu}^{63}$ & 4.5 & $3.17 \pm 0.18$ \\
\hline & $\mathrm{Cu}^{65}$ & 2.0 & $1.39 \pm 0.22$ \\
\hline & $M 0^{88}$ & 0.18 & $9.9 \pm 1.1$ \\
\hline & $\mathrm{MO}^{100}$ & 0.199 & $4.06 \pm 0.23$ \\
\hline & $W^{186}$ & 35 & $476 \pm 50$ \\
\hline$U^{298}$ & (Capture) & 2.73 & $280 \pm 10$ \\
\hline $\mathrm{U}^{235}$ & (Fission) & 561 & $263 \pm 9$ \\
\hline $\operatorname{In}^{115}$ & $(54 M)$ & 156 & $2550 \pm 80$ \\
\hline $\operatorname{In}^{115}$ & $(135)$ & 38.7 & $650 \pm 30$ \\
\hline
\end{tabular}

(a) Values of Resonance Integrais are directly propurtional to value of $g \sigma_{t h}$ assumed. For revisions of thermal cross sections, revised resonance integrals should be used.

(b) Resonance Integrals do not include epicadmium $1 / \mathrm{v}$ capture except for $U^{235}\left(E_{c d}=0.600 \mathrm{ev}\right)$ and $\operatorname{In}^{21}{ }^{21}$ $\left(E_{c d}=0.622 \mathrm{ev}\right)$. 


\section{DISCUSSION}

\section{THEORETICAL}

DEFINITION OF RESONANCE INTEGRAL

The resonance absorption integral is an index of the epithermal neutron absorption by a material in a reactor flux. Since most thermal reactors have an epithermal flux that varies approximately as $1 / \mathrm{E}$ with the neutron energy, $\mathrm{E}$, resonance integrals are usually defined with respect to such a $1 /$ E flux distribution.

If the microscopic absorption cross section of the material is $\sigma_{a}(E)$, and if there are no self-shielding effects, the tintial enlluermal rosonanoe integral is given by

$$
(R I)^{\text {Tot }}-\int_{E_{0}}^{\infty} \pi_{a}\left(F_{1}\right) \frac{d E}{E}
$$

where the lower energy limit $E_{O}$ is normally taken to be five times the energy $\mathrm{kT}$ which characterizes the Maxwellian thermal flux distribution (4). The value of $\mathrm{kT}$ depends on the temperature; for a temperature of $20^{\circ} \mathrm{C}, \mathrm{kT}$ is $0.0253 \mathrm{ev}$. The temperature dependence of the resonance integral may be eliminated by any one of several practical devices. One such device is to specify a lower energy limit greater than five times the highest value of $\mathrm{kT}$ encountered. A value of $\mathrm{E}_{\circ}=0.5 \mathrm{ev}$ is frequently used. Another device is to specify a lower energy limit determined by the effective cadmium cutoff energy. Wh1.e this latter method removes the temperature dependence, it Introduces a dependence on cadmium thickness and the degree of flux anisotropy. In addition, this method introduces a dependence on the manner in which the absorption cross section vilies with energy in the vicinity of the cadmium cutoff energy (which $1 \mathrm{~s}$ at approximately $0.5 \mathrm{ev}$ ). For absorvers that have resonances above 3 to $4 \mathrm{ev}$, the most convenient device is to define $R I^{R e s}$ as the total resonance integral minus the $1 / \mathrm{v}$ component. Th1s quantity is then indepondent of temperature and of $\mathrm{E}_{\mathrm{o}}$ over a wide range. It may be expressed as

$$
(R I)^{\text {Res }}=(R I)^{\text {Tot }}-(R I)^{I / v} \equiv \int_{E_{O}}^{\infty} \sigma_{a}(E) \frac{d E}{E}-\int_{E_{O}}^{\infty} \sigma_{t h} \sqrt{\frac{E}{E} \frac{t h}{E}} \frac{d E}{E}
$$

where $\sigma_{\text {th }}$ is the absorption cross section at the thermal energy, $\mathrm{E}_{\text {th }}$. 


\section{PAGES 9 to 10 WERE INTENTIONALLY LEFT BLANK}


for this effect are 0.985 for gold and 0.937 for indium at a cadmium thickness of 0.030 inch. Corrections for $W^{186}$ are discussed in a later section. Shielding by cadmium is assumed to be negligible for the other, detector folls of the present experiment.

\section{TECHNIQUE}

METHOD (EXPERIMENTAL)

Foll activations were made in the standard Pile (SP) of the Savannah River Laboratory (SRL). The: $S P^{(0,10)}$ is a watercooled, graphite-moderated reactor, fueled with fully enriched uranium. -. The construction is similar to that of the Thermal Test Reactor (TTR)(21). The 1rradiations were conducted in the central thimble, a 3.00-inch-diameter tube along the axis of the reactor. Solid graphite cylinders 3 inches in diameter were loaded in one end of the central thimble up to $3 / 4$ inch past the reactor midplane. The remainder of the thimble contained the foll holders as indicated in Figure 1. Folls were affixed to the aluminum spinner discs with a single thlckness of cellophane tape. Four bare and four cadmlumcovered folls were placed on each disc. The aluminum rod and a serles of "Teflon" blocks served as a mandrel so that the spinner discs could be rotated during the irradiations, thus eliminating the effect of possible flux gradients across the cavity. The endmost spinner disc served to position the holder. During the irradiations just enough pressure was applied to keep this disc in contact with: the graphite end face. This allowed accurate repositioning after removal of the holding apparatus.

The structural materials of the irradiation apparatus were selected for their. nuclear as well as their mechanical properties. Both aluminum and "Teflon" have low slowing down powers, small thermal neutron absorption cross sections, small scattering cross sections, and negligible resonance effects. The full set of eight cadmlum covers was used in each irradiation whether or not the full elght sets of f'olls were used. This served to standardize the thermal neutron flux depression in the vicinity of the cavity since the variation in total neutron absorption in the cavity due to the different folls was negligible compared to the constant absorption of the cadmium and the structural materials. The cadmium covers were in the form of cylindrical plilboxes and were 0.030 inch thick on each race as well as at the cdge. 


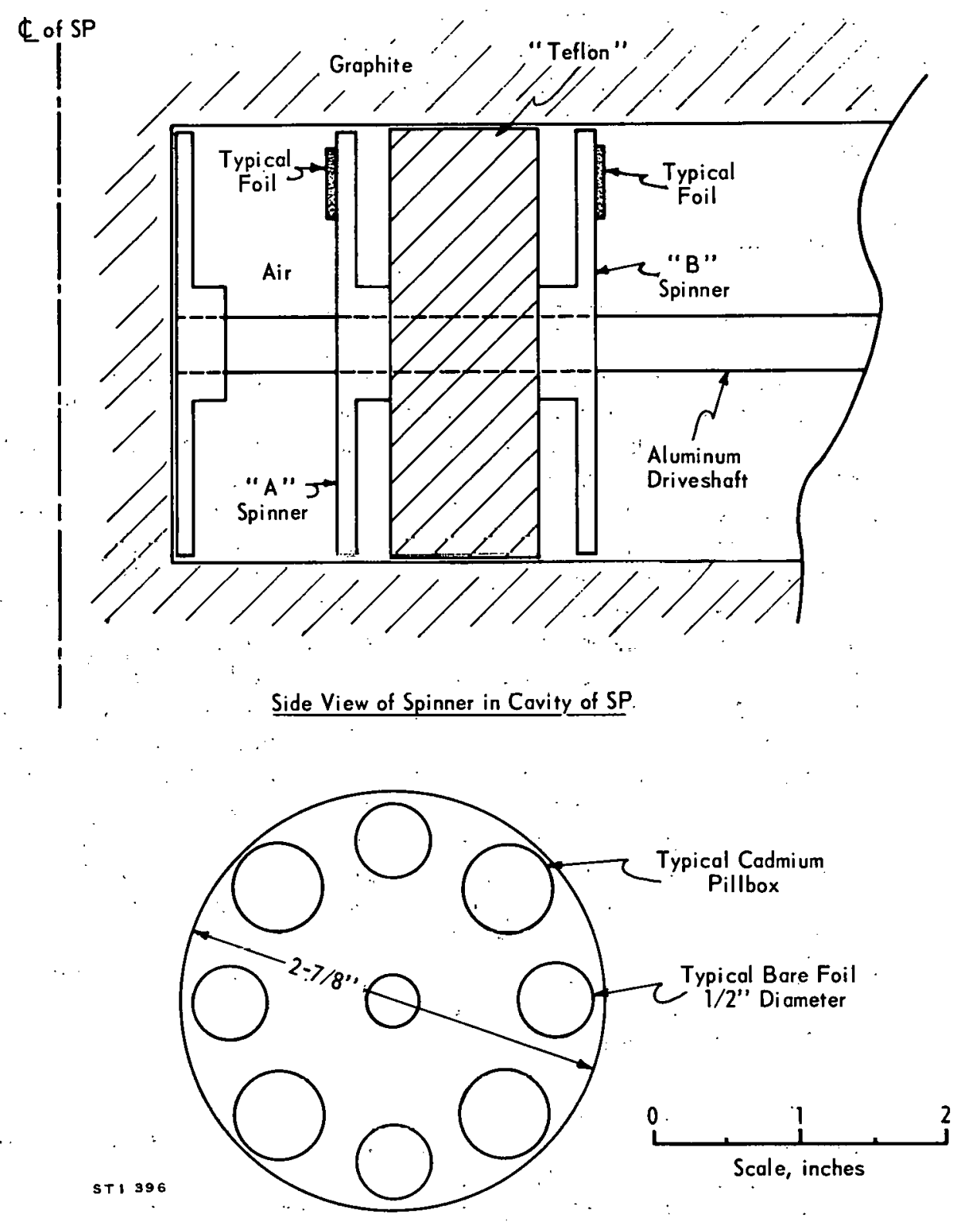

End View of Aluminum Foil Holding Dise

FIG. I FOIL IRRADIATION APPARATUS 


\section{GOLD CALIBRATION}

The method of measuring resonance integrals by cadmium ratios requires the use of a reference materlal whose thermal cross section and resonance integral are precisely known. In principle, a material whose activation cross section has a $1 / \mathrm{v}$ energy dependence would be an 1deal standard except that no such material. exists, and if it did, its use would require a knowledge of the preclse effective cadmium cutoff energy. What is actually done is to use an activating reference material that has 1 tself. been calibrated to a boron counter as the $1 / \mathrm{v}$ detector. Recent measurements by J1rlow and Johansson $(7)$ of the resonance integral of gold now make gold a suitable reference material. In those measurements a beam flux permitted the comparison to be made between the gold activations and boron counters of conventional size and shape. In addition the effective cadmium cutoff energy was determined by means of a neutron chopper. They have thus given a careful calibration of gold in terms of a $\mathrm{I} / \mathrm{V}$ absorber. The value obtained for the total epicadmium resonance activation integral for infinitely thin gold folls was 1535 . \pm 40 barns, based on a thermal cross section of 98.8 barns and a cutot't energy of $0.49 \mathrm{ev}$.

In the present experiment, half-1nch-diameter gold folls of approximately $10 \mathrm{mg} / \mathrm{cm}^{2}$ were used as the basic reference folls. Foll thicknesses were determined by weighing the individual folls. Since foll thicknesses varied by as much as 10\% from foll to foll and since this difference in foll thickness is sufficient to cause appreclable difference in the amount of resonance self-shiclding, 1t was necessary to make a self-shielding correction as well as the normal weight correction to the individual measured cadmium ratios. Although experimental data have been obtained( 9$)$ on which to base such corrections, it was felt that corrections based on calculations from basic resonance parameters would be more accurate. The calculations follow the procedure given in Appendix A and Include depressions for the nine strongest resonances, the epicadmium $1 / \mathrm{v}$ component, and the thermal flux. The effect of Doppler broadening is also included. The results of the calculation are presented in Table II.

The resonance flux is based on a cadmium cutoff energy of $0.622 \mathrm{ev}$. The expression "flux depression factor" is a shorthand notation to describe the activity per unit weight of the l'o1ls relative to lie activity por unit weight of an infinitely thin foil. 
The data of Table II are shown graphically in Figure 2 where they are compared to the earlier experiments (s) at the Savannah River Laboratory and to some new measurements. In this figure the experimentally measured quantities, the ratios of $[\mathrm{CR}-1]^{\circ}$ for an infinitely thin foll pair to $[C R-1]^{X}$, for a foil pair of finite thickness, are compared to the theoretical equivalents, the activation ratios of the last column of Table II. The earlier experimental data have been renormalized to allow for the fact that the calculated extrapolation to zero foll thickness is different from the extrapolation used in the earlier experiment. This renormal1zation reduces the experimental ratios to 0.980 times the earlier values.

The agreement of the calculated values with the expertmental valuod io vary good excepl ln lhe thlckness range from 10 to $30 \mathrm{mg} / \mathrm{cm}^{2}$. In order to determine whether the experiment or the calculation is in error in this range, a lemedsurement with both thin and thick gold foils (0.2'2 and $10 \mathrm{mg} / \mathrm{cm}^{2}$ ) was made under the present experimental conditions. Cadmium ratios were taken l'irst with the paired folls alternately bare and cadmium covered and then with the positions reversed. The geometric mean cadmium ratio of the normal and reversed positions was used after making corrections for the small difference of resonance self-shielding among the thick folls. As seen from Figure 2, the present experiment agrees w1th the calculated curve. The three data points shown actually represent the average of a total of 18 cadmium ratio measurements. The validity of the calculations may also be demonstrated by comparing the zero thickness cadmium ratios as calculated from the $10 \mathrm{mg} / \mathrm{cm}^{2}$ folls to those calculated from the very thin folls. The thicker folls give zero thickness cadmium ratios of $2.005 \pm 0.008$ for " $A$ " position and $2.086 \pm 0.008$ for " $B$ " position compared to $2.010 \pm 0.010$ and $2.093 \pm 0.010$ for the corresponding cadmium ratios from the very thin folls. The validity of the computed depression factors of Table II is further verifled by comparison with recent measurements by Brown (12), et al. Our computations agree closely with all the experimental points but deviate markedly from the interpolation curve drawn by these authors through their somewhat more limited number of data points.

The thernal cross section, $\sigma_{\mathrm{th}}$, of gold at $0.0253 \mathrm{ev}$ is taken to be 98.8 barns $(4,7)$, the value of $g$ in Equation 7 is 1.006 at an estimated neutron temperature of $30^{\circ} \mathrm{C}$, and the value of the resonance component of the resonance integral is $1490 \pm 40$ barns $^{(7)}$ to which must be added a $1 / \mathrm{v}$ component of 40 barns for a cadmium cutoff energy of $0.622 \mathrm{ev}$. The value of the resonance shielding factor is 0.985 for gold covered by 0.030 -inch-thick cadmium ${ }^{(8)}$. It is important to note that 
Computed Resonance and Thermal Depression Factors for Gold Foll Activations in an Isotropic Flux in a Cavity

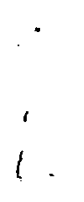

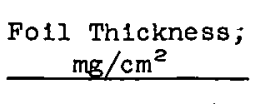

0.05

0.1

0.2

0.5

0.75

1.0

2.0

3.0

5.0

7.5

10

20

40

60

120

240
Resonance Depression

Factor, $F^{\text {Res }}$

0.994

0.987

0.975

0.950

0.931

0.919

0.867

0.828

0.763

0.698

0.645

0.521 .

0.410

0.347

0.264

0.202
Thermal Depression

Factor, $F^{\text {th }} \quad \underline{F}^{\text {Res }} / F^{\text {th }}$

$$
1.000
$$

0.994

1.000

0.987

1.000

0.975

1.000

0.950

0.999

0.932

0.999

0.920

0.998

0.869

0.997

0.830 .

0.995

0.767

0.994

0.702

0.992

0.650

0.985

0.529

0.969

0.423 .

0.959

0.362

0.930

0.283

0.229

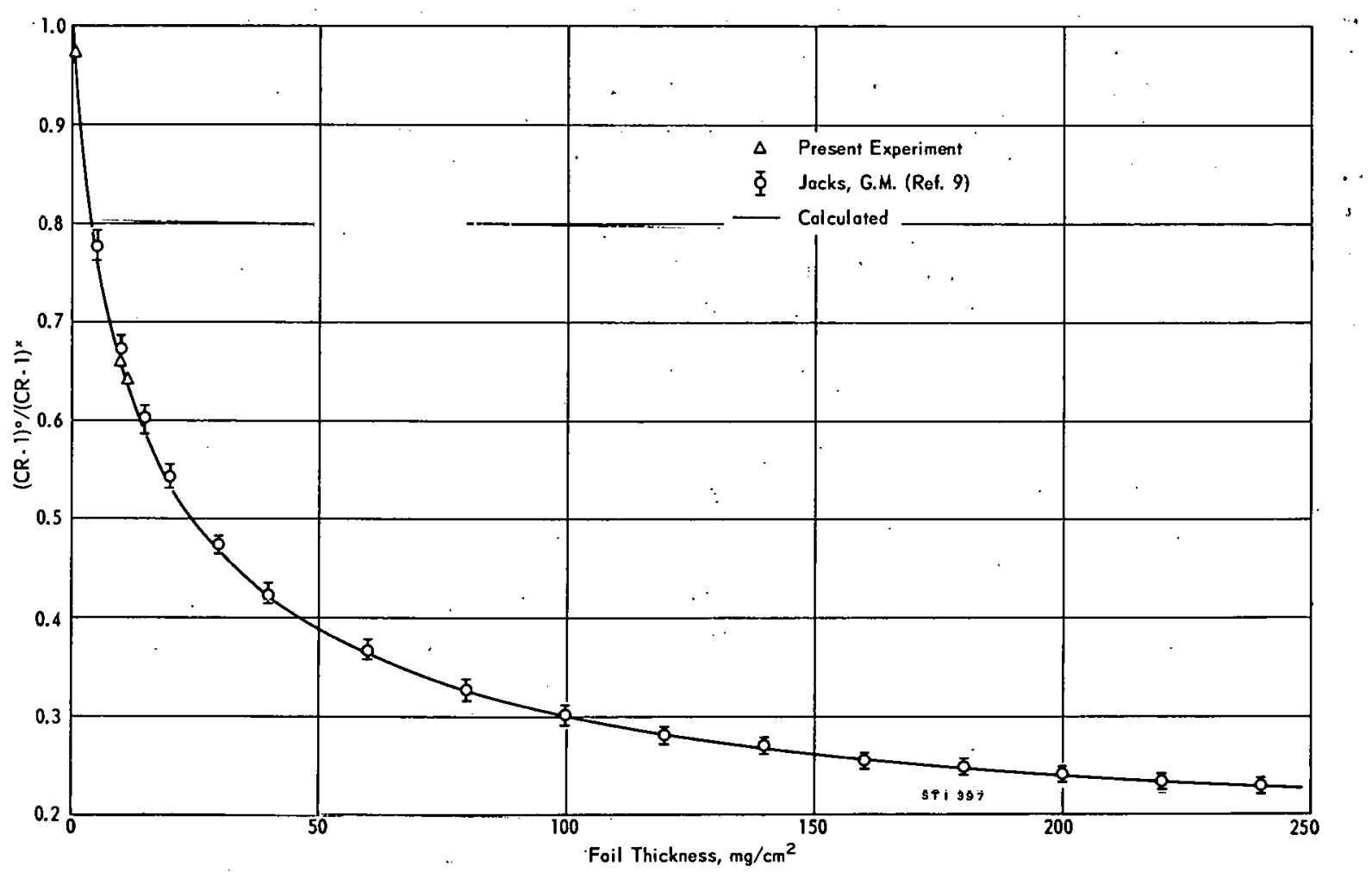

FIG. 2 THICKNESS CORRECTIONS FOR CADMIUM RATIOS OF Au ${ }^{197}$ FOILS (Isotropic Flux in Covity) 
this same correction is 1mplic1tly made in the reference experiment(7). From these cross sections and the cadmium ratios derlved from the $10 \mathrm{mg} / \mathrm{cm}^{2}$ folls one obtalns the following calibration relations for the present experiment.

$$
\begin{aligned}
& \left.\left(\frac{\mathrm{RI}^{\mathrm{Tot}}}{\sigma_{\mathrm{th}}}\right)=15.00[\mathrm{CR}-1]^{-1}\right]^{\text {"A" Position }} \\
& \left(\frac{\mathrm{RI}^{\mathrm{Tot}}}{\sigma_{\mathrm{th}}}\right)=16.21[\mathrm{CR}-1]^{-1} \text { "B" Position } \\
& \text { EFFECTIVE RESONANCE INTEGRALS }
\end{aligned}
$$

\section{EFFECTIVE RESONANCE INTEGRALS -}

$\mathrm{Cu}^{63}$ AND $\mathrm{Cu}^{65}$

Copper is frequently used as a neutron poison for reactor experiments. Its utility in this service depends on a preeise knowlede uf 1 ls litrilld uroes section ás we $\perp$ as 1 ts resonance integral. Although the thermal cross section of $3.77 \pm 0.04$ barns (13) is known sufflclently accurately, the value of the resonance integral and 1 ts dependence on foll thickness have not been measured precisely. An added complication is that two isotopes, $\mathrm{Cu}^{63}$ and $\mathrm{Cu}^{65}$, contribute to the resonance integral, but in many reactor experiments only the 12.8-hour activity from neutron capture by $\mathrm{Cu}^{63}$ can be counted conveniently. The results of the present experiment provide the basis for computing the total copper absorption from measurements of the 12.8-hour activity alone.

Folls were made of metallic copper and ranged in thickness from 0.002 to 0.020 inch. Toll thicknesses were based on measured foll weights and a copper density of $8.94 \mathrm{pm} / \mathrm{cm}^{3}$. The activated folls were counted on a scintillation counter system using sodium lodide (TI) crystals.

The 5-minute activity of $\mathrm{Cu}^{65}$ was counted at an integral blas of $0.6 \mathrm{Mev}$ in order to minimize background from the $0.51-\mathrm{Mev}$ positron annihilation radiation of $\mathrm{Cu}^{63}$. Bare and cadmium-covered folls were counted alternately to minimize errors from decay time corrections. Background counts to determine the contribution from the 12.8-hour $\mathrm{Cu}^{63}$ activity during the counting of the $\mathrm{Cu}^{65}$ were made approxinately 50 minutes after the initial counts and were extrapolated to the initial counting period.

For the $\mathrm{Cu}^{63}$ measurements, the 12.8-hour activity was measured several hours after irradiation at a blas of 0.4 Mev. The small differences in foll thickness were taken into account by simple weight corrections of the activities. 
The results of the measurement are tabulated in Table III and are shown graphically in Figure 3. In Table III the column labeled Fuel Position indicates whether the foll pairs were on Spinner "A" or Spinner "B" of Figure 1. The thermal flux depression factors are derived from the measured subcadmium activities of the present experiment, 1.e., by ratioing the measured activities with the product of the relative thermal neutron exposure times the foll welght. These factors can be measured to a sufficient accuracy for copper, and, moreover, the calculational method given in Appendix A may be in error for copper because of the high ratio of scattering to absorption cross sections. The column RIEff gives the number obtained from Equation 8 for the total resonance integral above $0.622 \mathrm{ev}$ including the $1 / \mathrm{v}$ component. The final column, $\mathrm{RI}$ Eff, is the total resonance integral minus the $1 / \mathrm{v}$ component. The values are based on thermal cross sections of 2.0 barns for $\mathrm{Cu}^{65}$ and 4.5 barns for $\mathrm{Cu}^{63}$ to make them consistent with values given by Dahlberg(14), et al.

Flgure 3 shows the variation of effective resonance integral with foll thickness and compares the present measurements to those of Dahlberg(14), et al., and of Bennett(15). In Figure 3, Bennett's integrals have been re-evaluated on the basis of the calculated thickness correction for gold given in Table II and on the basis of the same gold resonance integral and $\mathrm{Cu}^{65}$ thermal cross section used in the present report. The values initially quoted by Bennett are based on boron cadmium ratios and are even lower than those shown in Figure 3. The discrepancy between Bennett's results and those of the present experiment is possibly due to a deviation from a $1 / E$ flux in the spectrum of the PCTR in which Bennett's measurements were made. The resonance self-shlelding factors measured by Bennett for the very thin folls were used to extrapolate the present results to zero thickness. The results of the measurements by Dahlberg, et al., are also indicated. The data points at the origin are Dahlberg's calculated extrapolation to zero thickness. Because their experiment was done in a beam flux, only the extrapolation to zero thickness is directly comparable to the results of the present experiment. The values from the present experiment of $3.17 \pm 0.18$ and $1.39 \pm 0.22$ barns compare closely w1th the values of $3.09 \pm 0.15$ and $1.38 \pm 0.23$ barns given by

Dahlberg, et al. The major part of the indicated uncertainties lies in the thermal cross sections for copper and in the value of the resonance integral for gold; uncertainties common to both experiments. If these are removed, the relative uncertainties are \pm 2 to $3 \%$ of the quoted resonance integrals and the comparison is seen to be quite good. 
TABLE III

Measured Cadmium Ratios and Resonance Integrals for $\mathrm{Cu}^{63}$ and $\mathrm{Cu}^{65}$

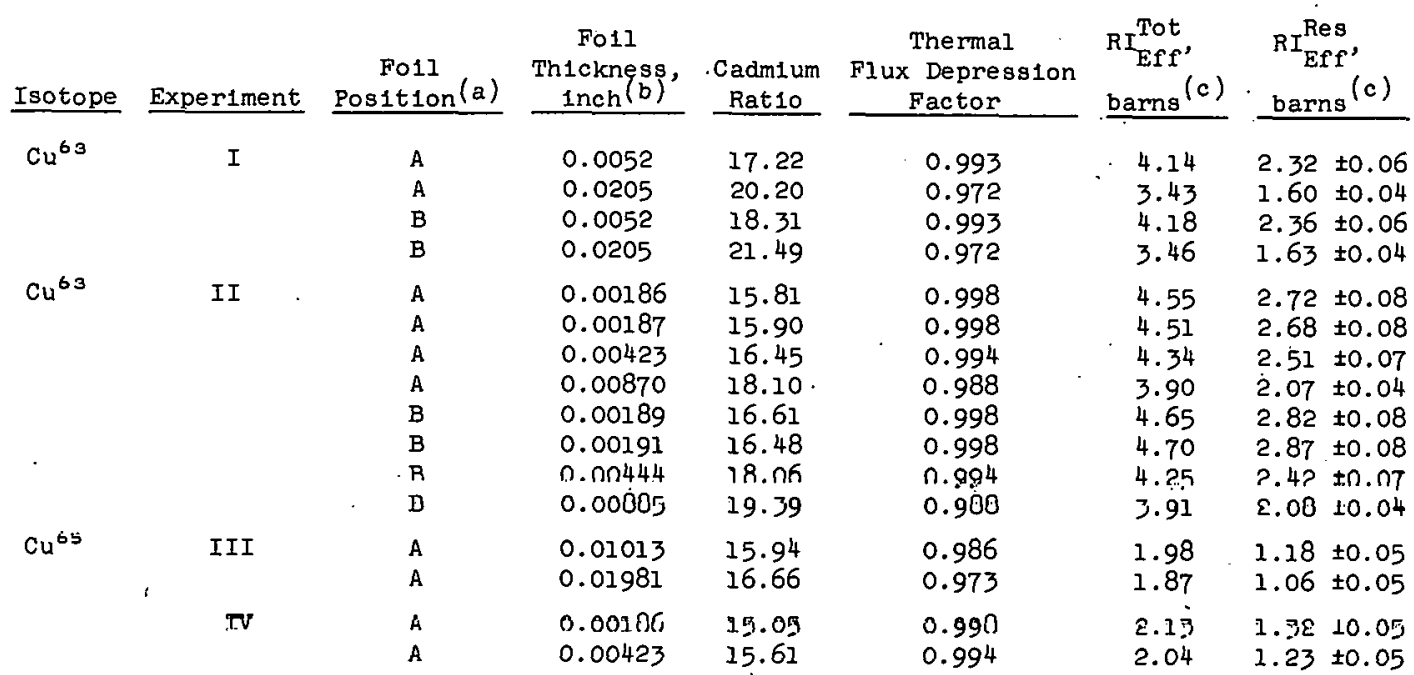

(a) See Figure 1

(b) Based on density of $8.94 \mathrm{gm} / \mathrm{cm}^{3}$

(c) Based on $\sigma_{t h}=4.5$ barns for $\mathrm{Cu}^{63}$ and $\sigma_{\text {th }}=2.0$ barns for $\mathrm{Cu}^{65}$ (Ref. 14)

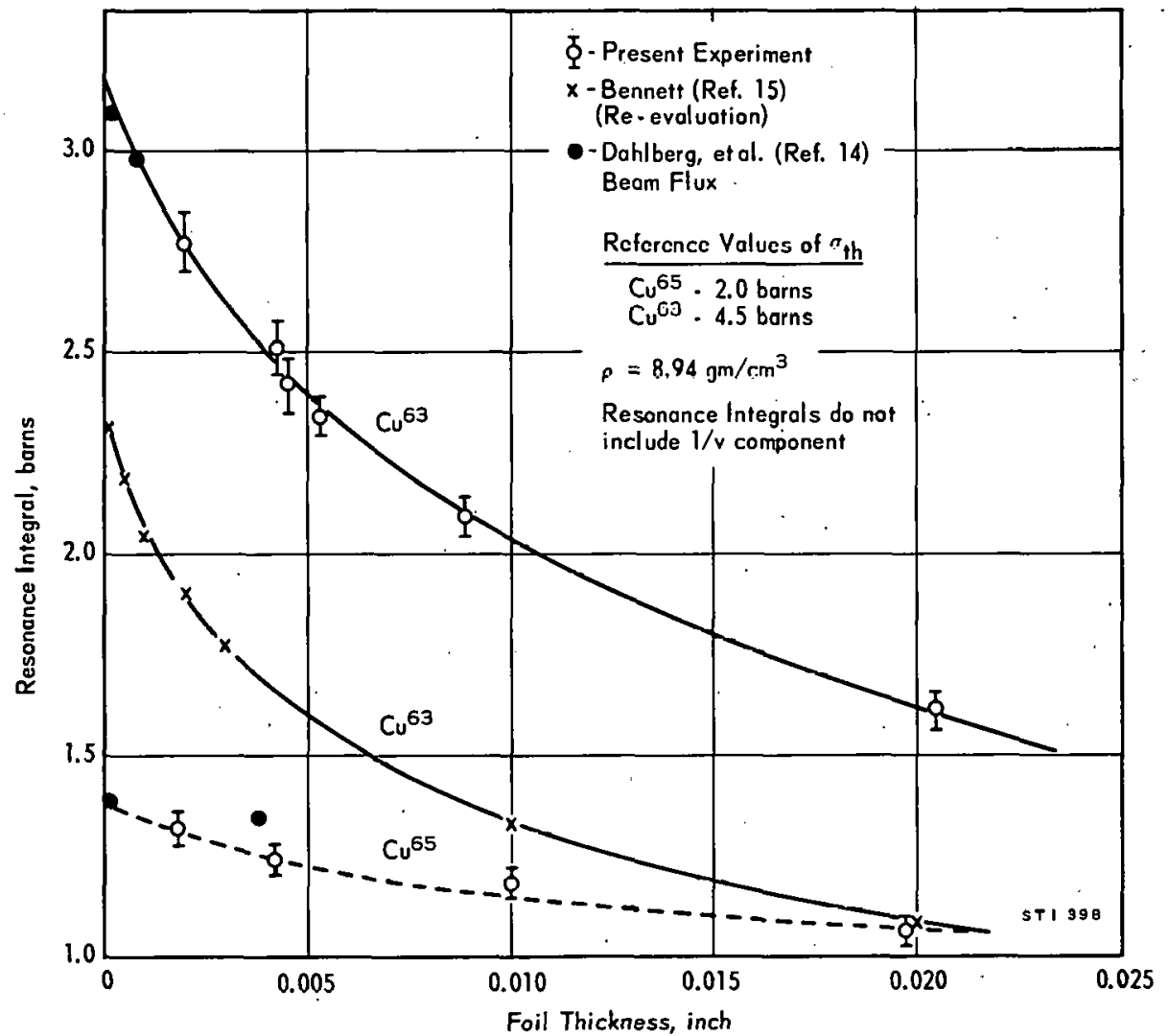

FIG. 3 EFFECTIVE RESONANCE INTEGRAL FOR Cu ${ }^{63}$ AND Cu 65 AS A FUNCTION OF FOIL THICKNESS (Isotropic Flux in Cavity) 
Mo ${ }^{98}$ AND Mo ${ }^{100}$

The molybdenum 1sotopes $\mathrm{MO}^{98}$ and $\mathrm{Mo}^{100}$ are presumed to be useful as resonance neutron detectors in reactor experiments in that both isotopes have only a single tabulated resonance at an energy of several hundred electron. volts and both have a high ratio of resonance to $l / v$ absorption. Under the conditions of the present experiment, these are the only two isotopes of natural molybdenum which give detectable activations.

Folls were made from sheets of molybdenum metal with a nominal thickness of 0.0005 and 0.001 inch. Foils thicker than 0.001 inoh were ontained by stacking. The activated folls were counted on the standard scintillation counter system. The counting procedure was somewhat complex because of the two-step decay schemes of the activated isotopes. The Mo ${ }^{99}$ formed from neutron capture by Mo ${ }^{98}$ primarily decays with a 67-hour half-11fe by $\beta$ and $(\beta, \gamma)$ emission to an 1someric state in $\mathrm{Tc}^{99}$. This isomeric state in turn decays with a 6.0-hour half-life to the ground state of $\mathrm{Tc}^{99}$ by emission of an $0.14-\mathrm{MeV}$ gamma ray. The Mo101 formed from neutron capture by Mo100 decays with a 14.6-minute half-life by $(\beta, \gamma)$ emission to the ground state of $\mathrm{Tc}^{101}$. This isotope in turn decays with a 15-minute half-life by $(\beta, \gamma)$ emission to the ground state of $\mathrm{Ru}^{101}$.

Because of the complicated time behavior of the Moloo activations, a reference foll technique was used to measure the time decay characteristics for each experiment. Pairs of cadmlum-coveren and bare folls were counted alternately to minimize the magnitude of the time correction for edch pair. In order to Elmpliry. the background correction for the unwanted activity from the $\mathrm{Mo}^{98}$, it was necessary to blas above the 0.14 -Mev gamma-ray energy of the isomeric state of $\mathrm{Tc}^{99}$. A bias of $0.200 \mathrm{Mev}$ was determined to be sultable and a simple exponential time correction with a 67-hour half-life then used for the background correction.

The activity of the $\mathrm{Mo}^{98}$ was counted one to two days after the irradiation to minimize possible contamination by activation of $\mathrm{Mo}^{92}$ with its 6-hour half-life. A bias of $0.100 \mathrm{Mev}$ was used to increase the count rate by including the gamma rays from the isomeric transition in $\mathrm{Tc}^{99}$. During the same interval the folls were counted at a bias of $0.200 \mathrm{Mev}$ to provide the background data for the shortlived activity. 
The experimental results are shown in Table IV and Figure 4. Resonance integrals were computed directly by Equation 8 for thermal cross sections of $0.18 \pm 0.02$ barn for Mo ${ }^{98(14)}$ and $0.199 \pm 0.005$ barn for Moloo(16). The computed thermal flux depression was negliglble for the range of foll thicknesses used. The indicated uncertainties in Figure 4 are for the present experiment and do not include errors in thermal cross sections or in the resonance integral of gold. The curves shown on Figure 4 are normalized to the experimental data, but their shape was calculated from listed resonance parameters (1) for the single tabulated resonance of each isotope using the procedure given in Appendix A. Even though, as discussed later, the absolute values of the calculated resonance integrals did not agree with those measured, the calculated depression factors fit the data quite well.

Figure 4 also includes a comparison of the present experiment with other measurements. Dahlberg(14), et al., extrapolate their measurements on $\mathrm{Mo}^{98}$ to a zero thiolnedo resunance integral of $10.7 \pm 2.5$ barns compared to the value of $9.9 \pm 1.1$ barns obtained from the present experiment. It seems probable, however, that their extrapolation to zero thickness is in error. If the resonance flux depression factor for the 1r beam experiment is calculated from the same

TABLE IV

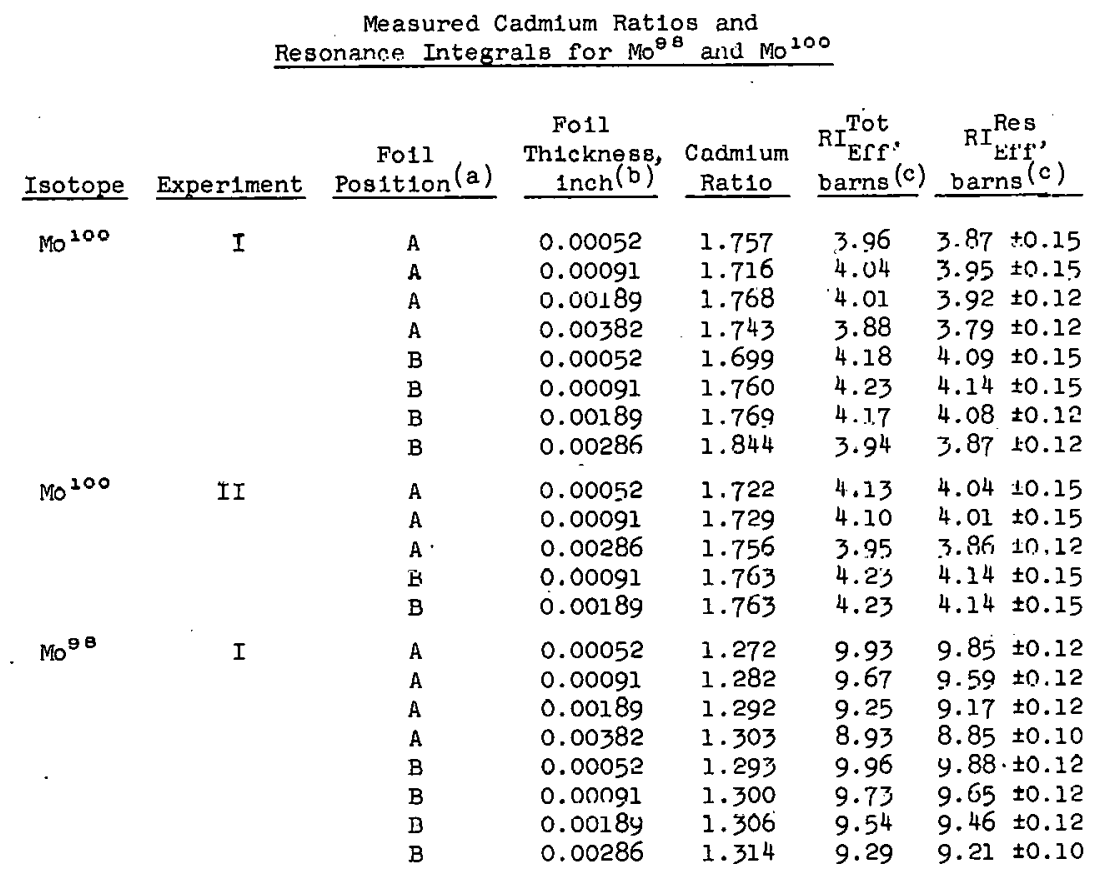

(a) See F1gure

(b) Based on a density for molybdenum density of $10.2 \mathrm{gm} / \mathrm{cm}^{3}$

(c) Based on $\sigma_{t h}=0.199 \pm 0.005$ barn for Moloo (Ref. 17) and $\sigma_{t h}=0.18$ \pm 0.02 barn for Mo ${ }^{98}$ (Ref. 14). Indicated probable errors are for present measurements only and do not include thermal cross section and gold resonance integral uncertainties. 
resonance parameters which fit the present experiment, an infinite dilution resonance integral of 9.8 barns is obtained from their data. This agrees very closely with the present results. As in the case of copper, the experimental uncertainties for comparison between experiments are much smaller than the absolute uncertainties.

Thermal cross sections and resonance integrals for $\mathrm{Mo}^{98}$ and Mo. ${ }^{100}$ have also been measured by Cabell $(16,17)$. For Mo 100 he ob.talns (16) a thermal cross section of $0.199 \pm 0.005$ barn and a resonance integral of $3.73 \pm 0.20$ barns. For $\mathrm{Mo}^{98}$ he obtains (17) a thermal cross section of $0.136 \pm 0.003$ barn and a resonance integral of. $6.69 \pm 0.13$ barns. The 6.69-barn value is increased to $8.85 \pm 0.17$ barns for a thermal cross section of 0.18 barn. Th1s higher value is shown in Figure 4 so that the different measurements can be compared on a common basis. Cabell's value for the Mo ${ }^{98}$ thermal cross section would reduce all resonance integrals for $\mathrm{Mo}^{98}$ in Table. IV and Flgure 4 by $24.5 \%$. Cabell's values of the resonance integrals for both isotopes are about 10\% lower. than those of the present experiment and those given by Dahlberg. The difference is belleved to be due to a deviation from a $1 / E$ spectrum in the neutron flux used by cabell.

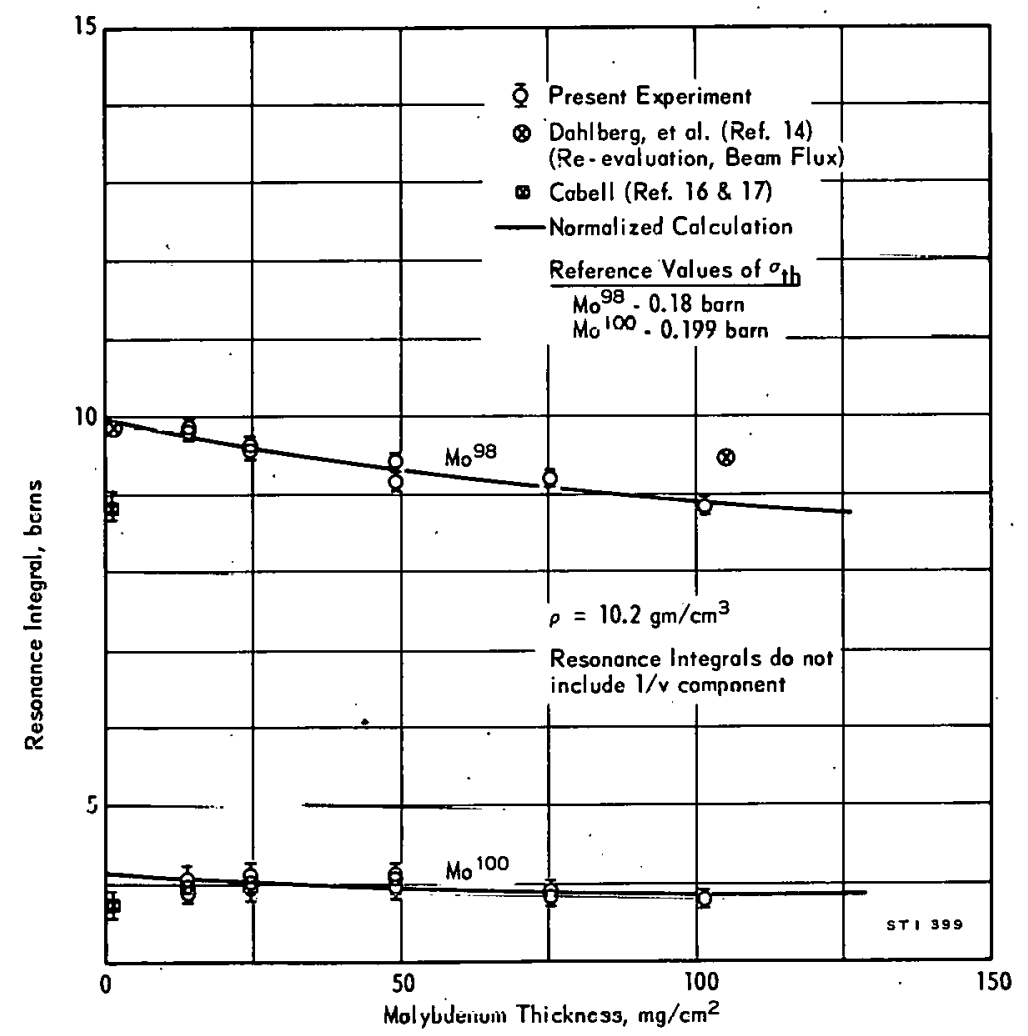

FIG. 4 EFFECTIVE RESONANCE INTEGRAL FOR Mo ${ }^{98}$ AND $M_{0}^{100}$ AS A FUNCTION OF FOIL THICKNESS (Isotropic Flux in Covity) 
It is of interest to compare the calculations of the resonance integral with the measurements. From the tabulation of Hughes and Schwartz(1), $\mathrm{MO}^{98}$ has a single resonance at an energy of $480 \mathrm{ev}$ and $\mathrm{Mo}^{200}$ has a single resonance at $367 \mathrm{ev}$. Under these conditions the resonance integral may be calculated from the resonance parameters ${ }^{(5)}$ or from the thermal cross section $(18)$ by the following relations.

$$
\begin{gathered}
\mathrm{RI}=2 \pi\left(\mathrm{E}_{\mathrm{th}} / \mathrm{E}_{\mathrm{o}}\right)^{\frac{1}{2}} \sigma_{\mathrm{th}} / \Gamma \\
\mathrm{RI}=4.10 \times 10^{6} \mathrm{~g} \Gamma_{\mathrm{n}} \Gamma_{\gamma} / \Gamma_{\mathrm{o}}{ }^{2}
\end{gathered}
$$

Here $E_{t h}$ is the energy in ev at which the thermal cross section $\sigma_{\text {th }}$ is glven, $\mathrm{E}_{\mathrm{O}}$ is the resonance energy in ev, the $\Gamma$ 's are reaction widths in $e v$, and $g$ is a welghting factor which is unity for both isotopes of molybdenum. Table $V$. compares measured quantities with calculations made by the above equations and standard values of resonance parameters $(1,19)$. The $1 / v$ component is not included.

\section{TABLE V}

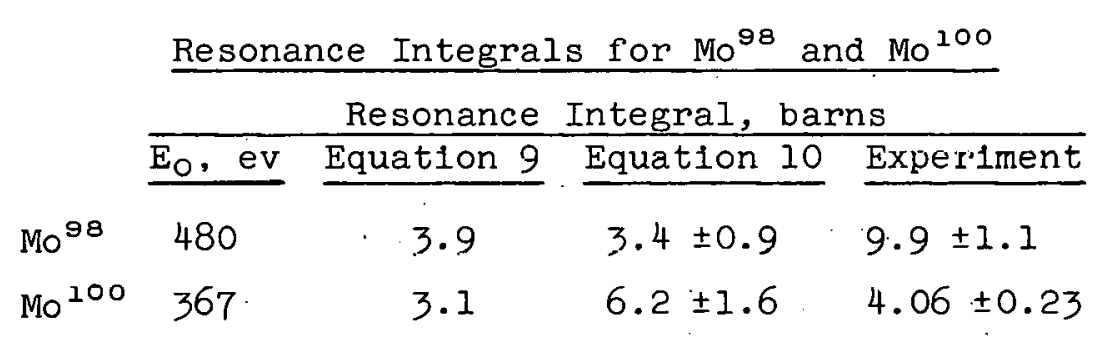

For Moloo the measured value lies between the valuco calculated by the two methods, and appears consistent with the accuracy expected by the two methods. For Mo ${ }^{98}$, however, the measured value is about three times that calculated by either method and is well outside the expected uncertainty of the calculations. This result indicates that a second unidentified resonance is responsible for the major part of the resuriance integral of $\mathrm{Mo}^{\text {gy }}$. Because of the size of this resonance it almost certainly is lower in energy than the $480 \mathrm{ev}$ of the identified resonance. This in turn implies that one of the lower energy resonances $(1,10)$ for molybdenum is misidentified or that an accidental coincidence of resonances by two isotopes has occurred. 
Verification of this assumption is given by an experiment described in Appendix $D$ in which the attenuation of the resonance activation by successive layers of boron absorber is measured. The experimental results suggest that at least half of the resonance integral for Mo ${ }^{98}$ lies in the energy range from 70 to $200 \mathrm{ev}$. The presence of a lower energy resonance for $\mathrm{Mo}^{98}$ has also been observed by Furr $(20)$ in a beam transmission measurement. In addition, the experiment described in Appendix $D$ suggests that the effective resonance energy for Mo ${ }^{100}$ is considerably higher than the $367 \mathrm{ev}$ of the tabulated resonance. Possible explanations are incorrect isotopic designations of the molybdenum resonances or accidental colncidences of resonance energies. In either event, the present experiment indicates that neither isotope is sultable for use in reactor spectrum measurements in which a single dominant resonance is required.

It is interesting to note from Figure 4 that the resonance flux depression calculated for Mo ${ }^{98}$ from the resonance parameters for the identified 480-ev resonance fits the experimental data very closely. This implies that any second resonance must have approximately the same maximum absorption cross section as the 480-ev resonance. Instead of assuming a second resonance, one may assume that the radiation width, $\Gamma \gamma$, for the $480-e v$ resonance is in error, and that Instead it should be obtained from the measured resonance integral and Equation 10. The resulting parameters, however, give a.calculated flux depression with a slope about four times that shown in Figure 4, which clearly does not agree. with the experiment. This gives further evidence of the existence of a second resonance which has a maximum absorption cross section approximately equal to that at $480 \mathrm{ev}$. S1milar arguments can also be advanced for $\mathrm{Mo}^{100}$.

$\mathrm{Na}^{23}$

Sulluin has two intoresting applicatinns for reactor spectrum measurements. First, it approximates the 1 deal $1 / \mathrm{v}$ detector better than any other activating material since the absorption from the single strong resonance is weak compared to the $1 / \mathrm{v}$ absorption and since that resonance 1 s a.t the relatively high energy of $2.85 \mathrm{Kev}$. Second, the presence of a single resonance at this high energy makes it a useful detector for spectrum measurements in the kllovolt region. Unfortunately, the features that make it useful for one of the two applications are undesirable for the other. In order to make the necessary corrections for either application, it is necessary to know precisely the value of the resonance integral. 
For this experiment, folls were made by two different methods. In one method small amounts of sodium b1carbonate were mixed with dental resin, which was then cast into sheets approximately 0.020 inch thick. Half-inch-diameter foils were punched from these sheets. Varlations in sodium content were taken into account by reversing cadmium and bare foll positions. A source of error with these foils is the effect of moderation by the contained hydrogen. Neutrons at energies just above the cadmium cutoff energy may enter the cadmium pillbox and be slowed down into the thermal energy region where the capture probability is considerably higher than at the initial epicadmium energy. This effect would cause an increase in activity of the cadmium-covered follo. In order to measure 1 ts magnitude, the activities of bare copper folls inside cadmium pillboxes were compared to copper activities obtained when foils of dental resin were ins.luted with the copper inside the cadmium piliboxes. With the assumption that the difference in activity was due entirely to slowing into the thermal region, the data for copper werc used to valculate the corrections applicable to the sodium foils. These corrections are indicated in Table VI.

A second set of hydrogen-free folls was made by compressing thin cakes of sodium carbonate against aluminum backing folls 0.015 inch thick and 0.5 inch in diameter. Aluminum foll 0.001 inch thick was wrapped around the folls to protect and contain the compressed cakes. When these folls were used, it was necessary to irradiate identical aluminum backing plates and foll covers to make corrections for activities from impurities in the aluminum as well as for the $\mathrm{Na}^{24}$ activity resulting from fast neutron capture by aluminum.

The results of the experiment are given in Table VI. Resonance integrals were determined by Equation 8 with a value of $0.52 \pm 0.010$ barn for the thermal absorption cross section of sodium. No systematic variation in cadmium ratio was noted with foll thicknesses; nor could a thickness correction be simply calculated since the extremely high ratio of scattering to absorption in the sodium resonance invalidates the conditions for which the corrections given in Appendix A apply. For these reasons the value of the resonance integral for sodium is taken to be the average of the values given in Table.VI. This average gives a resonance integral of $0.075 \pm 0.010$ barn compared to the value of $0.07 \pm 0.01$ reported by Dahlberg $(14)$, et al. 
Measured Cadmium Ratios and Resonance Integrals for $\mathrm{Na}^{23}$

\begin{tabular}{|c|c|c|c|c|c|c|c|}
\hline Experiment & $\begin{array}{c}\text { Foll } \\
\text { Position } \\
\end{array}$ & Foil Materlal & $\begin{array}{l}\text { Na Th1ckness, } \\
\mathrm{mg} / \mathrm{cm}^{2}\end{array}$ & $\begin{array}{c}\text { Mean } \\
\text { Cadm1um } \\
\text { Rat1o } \\
\end{array}$ & $\begin{array}{l}\text { Corrected } \\
\text { Mean } \\
\text { Cadmium } \\
\text { Ratio (a) }\end{array}$ & $\begin{array}{l}\mathrm{RI}_{\text {Eff' }} \\
\text { barn (b) } \\
\end{array}$ & $\begin{array}{c}\mathrm{RI}_{\text {Eff }}^{\text {Res }} \\
\text { barn } \\
\end{array}$ \\
\hline$I$ & $\begin{array}{l}\text { A } \\
\text { A } \\
\text { A } \\
\text { A } \\
\text { B } \\
\text { B } \\
\text { B }\end{array}$ & $\begin{array}{l}\mathrm{NaHCO}_{3} \text { in dental } \\
\text { resin }\left(60 \mathrm{mg} / \mathrm{cm}^{2}\right)\end{array}$ & $\begin{array}{l}2.7 \\
2.7 \\
2.7 \\
2.7 \\
2.7 \\
2.7 \\
2.7\end{array}$ & $\begin{array}{l}27.9 \\
27.7 \\
27.9 \\
27.2 \\
28.4 \\
28.9 \\
28.4\end{array}$ & $\begin{array}{l}29.9 \\
29.7 \\
29.9 \\
29.2 \\
30.3 \\
30.8 \\
30.3\end{array}$ & $\begin{array}{l}0.270 \\
0.272 \\
0.270 \\
0.277 \\
0.287 \\
0.282 \\
0.287\end{array}$ & $\begin{array}{l}0.059 \\
0.061 \\
0.059 \\
0.067 \\
0.076 \\
0.071 \\
0.076\end{array}$ \\
\hline II & $\begin{array}{l}A \\
A \\
A \\
B \\
B \\
B \\
B\end{array}$ & $\begin{array}{l}\mathrm{Na}_{2} \mathrm{CO}_{3} \text { in } \\
\text { aluminum envelope }\end{array}$ & $\begin{array}{r}26.0 \\
26.0 \\
26.0 \\
6.5 \\
6.5 \\
6.5 \\
6.5\end{array}$ & $\begin{array}{l}27.7 \\
21.3 \\
27.7 \\
30.1 \\
29.4 \\
30.1 \\
29.0\end{array}$ & & $\begin{array}{l}0.292 \\
0.297 \\
0.292 \\
0.290 \\
0.297 \\
0.290 \\
0.301\end{array}$ & $\begin{array}{l}0.081 \\
0.086 \\
0.081 \\
0.079 \\
0.086 \\
0.079 \\
0.090\end{array}$ \\
\hline
\end{tabular}

(a) See text for correction for dental resin.

(b) Based on $\sigma_{\text {th }}=0.520 \pm 0.010$ barn.

The resonance integral for sodium may be calculated from Equations 9 and 10. From the thermal cross section of 0.520 barn (Equation 9), a value of 0.067 barn is obtained. No direct measurements of the parameter $\Gamma_{\gamma}$ could be found in order to calculate the resonance integral from Equation 10. The value given for $\Gamma_{\gamma}$ in BNL-325(1) is also obtained from the thermal cross section by combining Equations 9 and 10 . The value given in BNL-325, incidentally, is misprinted. The value of $\Gamma_{\gamma}$ should be $U .34(\Omega 1)$ ev and not $3.4 \mathrm{ev}$.

$\underline{\mathrm{U}^{235}}$ FISSION

The $U^{235}$ folls were in the form of an alloy of aluminum and oralloy (93\% $\left.\mathrm{U}^{235}\right)$ with a total foll thickness of 0.010 inch or a $U^{235}$ thickness of $5.6 \mathrm{mg} / \mathrm{cm}^{2}$. Relative $U^{235}$ contents of the folls had been determined by activations in a thermal flux and these uranium concentrations were used to make corrections for the amall variations in the foil weights. Activities were obtained on the scintillation counter at a bias of $0.5 \mathrm{Mev}$. Blank aluminum folls, bare and cadmium covered, were also 1rradiated in order to make the small correction for activations induced in the aluminum. comparison experlments made with naluial uranium foils demonstrated that, although the $U^{238}$ caused a perceptible count in the natural folls, no correction for its activation was rcquired for the oralloy f'olls. 
The measured cadmium ratios for $U^{235}$ fission were $32.0 \pm 0.3$ for the "A" position and $33.9 \pm 0.3$ for the "B" position in the SP. Three sets of folls were used for each position with two separate irradiations for each set. Resonance integrals were calculated by Equation 8 with the cross sections and correction factors given below. The calculations showed that for the foll thickness used, the resonance flux depression was negligible, but the thermal flux was depressed by a factor of 0.976 . A value of $\sigma_{\text {th }}=577.01$ barns and a g factor of $0.973^{(4)}$ were used, with the $g$ factor based on a neutron temperature of $30^{\circ} \mathrm{C}$. The average resonance integral for the two positions is then 267 barns. A calculated correction of 1 barn must be applied to take into account the non-l/v character of the epithermal subcadmium fission cross section in Equation 7. This gives a final value for the $\mathrm{U}^{355}$ fissioll iesulance lritegral of $266 \pm 9$ barns including all uncertainties other than a deviation of the flux from a $1 / E$ energy dependence. The effective cadmilum cutof' $f$ energy t'or UEOS fisstons under these conditions is given by Hardy(22), et al. as $0.60 \mathrm{ev}$ for $0.030-1$ nch-thick cadmium. These authors also report a value of $267 \pm 11$ barns for the resoriance integral of $U^{235}$ flssion at a cutoff energy of $0.60 \mathrm{ev}$. However, a correction for the computed deviation of their spectrum from $1 / E$ reduces their value to $262 \pm 11$ barns.

Recent measurements (23) in the Thermal Test Reactor (TTR) at Hanford indicate that the effective neutron temperature at the center of the TTR is approximately $40^{\circ} \mathrm{C}$ above the physical temperature. The $g$ factor at this higher temperature gives a resonance integral 3 barns lower, or $263 \pm 9$ barns for the present measurement. Of the foll materials in the present experiment, $\mathrm{U}^{235}$ is the only one that deviates sufficiently from a $1 / v$ cross section so that the higher temperature would cause a perceptible difference in the measured resonance integral.

The resonance integral for $U^{235}$ fission has also been measured by Clayton (24) by two methods, both employing a $\mathrm{U}^{2 \ni S}$ flission chamber. In one case he compared cadmium ratios of the fission chamber with those for a $\mathrm{BF}_{3}$ counter. From this measurement, he obtains a value of $258 \pm 25$ barns corrected to a cadmlum cutoff energy of $0.60 \mathrm{ev}$. A second method, based on the fission chamber measurements and slowing down strengths measured by indium folls, glves a value of $271 \pm 25$ barns at a cutoff energy of $0.60 \mathrm{ev}$. The results of the present experiment are seen to agree quite well with all of the earlier measurements. 
All measurements based on fission product activations of the $U^{235}$ folls Implicitly assume that the 1sotopic distribution of fission products is the same for resonance fission as for thermal fission. Those with a fission chamber do not. Although the assumption is not strictly true $(25)$, numerically the error thus introduced is not important. This fact is demonstrated by the observed independence of the measured cadmium ratio of $U^{235}$ fission product activities on the time after irradiation at which the folls are counted.

$\underline{U^{238} \text { CANTURE }}$

The resonance integral for $U^{238}$ capture 1 s one of the most important parameters in the design and analysis of thermal reactors using natural or slightly enriched uranium. Many measurements have been made on highly self-shlelded uranium rods typical of those used in reactor design. Measurements have also been made on extremely thin folls. Such thin folls are frequently used as the standard whose resonance integral is known ( 281 barns) in order to make further resonance integral measurements on the highly shlelded rods. No prior measurements have been found for : uranium folls of intermediate thickness. These intermediate thicknesses are important for providing resonance integral calibrations for folls of the typical thickness used in reactor lattice experiments. In addition, they provide a sensitive check of various methods for calculation of resonance integrals.

Folls were llade of uranium depleted to 190 and $350 \mathrm{ppm}$. $\mathrm{U}^{235}$. One set of extremely thin folls was made by depositing uranyl nitrate dissolved in alcohol on folls of filter paper and allowing the solvent to evaporate. The average uranium thickness in these folls was $0.05 \mathrm{mg} / \mathrm{cm}^{2}$. Microscopic exarnination showed that the deposited crystals were extremely small (about 0.01 of the diameter of the individual paper flbers) and that the small crystals were dispersed through the 1ndividial fibers rather than on the surfaces. The effect of self-shielding in the individual microcrystals was judged to be negligible. A second set of folls was made from an alloy of 16.0 wt of the depleted uranium in aluminum. Foils ranging from near 0.001 to 0.020 inch thick were rolled from this material. Additional foll thicknesses were obtained by stacking individual folls. Metallic uranium folls made up the third set of depleted folls. Nominal foll thicknesses of $0.002,0.006$, and 0.010 inch were ava1lable. 
The activation measurements were obtained by scintillation counting of the $103-\mathrm{Kev} \mathrm{X}$-ray in the 2.3 -day decay of $\mathrm{Np}^{23.9}$ leading to $\mathrm{Pu}^{239}$. A single channel analyzer was used with an acceptance width of 90 to $116 \mathrm{Kev}$. The folls were counted during the time interval from 48 to 96 hours after the irradiation in order to minimize the fission product background. A small correction for the fission product activity was obtained by comparing natural uranium and depleted uranium activities for the uranium metal foils. For the thin foils of uranyl nitrate on filter paper and the folls of uranium in aluminum alloy, cadmium ratios were also obtained with the position of bare and cadmium-covered folls reversed in order to correct for minor variations in $U^{238}$ content of the paired folls.

The resilts of the measurement:s are shown in Table VTT. fion the computation of resonance integrals from the measured cadmium ratios by Equation 8 , the quantity $g \sigma_{t h}$ for $\mathrm{U}^{238}$ was taken to be 2.73 varns. 'l'hermal flux depression factors were negligible for all but the metallic uranium foils. The correction factor for the thickest metal folls was 0.984 .

The results are shown graphically in Figure 5. The resonance integrals are plotted against the parameter $\sqrt{\mathrm{S} / \mathrm{M}}$ where $S$ is the total surface area of the foll, including edges, in $\mathrm{cm}^{2}$ and $M$ is the total mass in grams of $U^{238}$ in the foll. For $U^{238}$ this parameter has several advantages over the simple thickness parameter used for the preceding isotopes. It gives a scale which conveniently separates the individual measurements for the thin foils and shows the structure in detail. Furthermore, it is the same parameter which is used to coordinate the measuremento for trick iuds and rod clusters.

In Figure 5, the experimental data are compared to calculations made by the procedure given in Appendix A. The calculations of the resonance flux depression are based on the tabulated resonance parameters ${ }^{(5)}$ for the nine strongest resonances, which at zero thickness make up $96 \%$ of the total resonance integral calculated for all resolved resonances. The calculations include the effect of Doppler broadening of the resonances, but neglect foll edge effects and energy exchanges resulting from resonance scattering. Because of the relatively small ratio of scattering to absorption for $U^{238}$ and because of the thinness of the folls these effects should be small. The calculated curve for slab geometry is seen to fit the experimental data very closely except for the thickest folls where the calculated curve is lower than the measurements. This is just what is expected, though, in that the calculations neglect the 
Measured Cadmium Ratios and Resonance Integrals for $U^{238}$ Capture

\begin{tabular}{|c|c|c|c|c|c|c|}
\hline Experiment & $\begin{array}{c}\text { Foli } \\
\text { Position (a) } \\
\end{array}$ & Fo1l Materlal & $\begin{array}{l}\text { Cadmium } \\
\text { Ratio } \\
\end{array}$ & $\begin{array}{l}\text { Tot } \\
\mathrm{RI}_{\mathrm{Ef} f^{\prime}}(\mathrm{b}) \\
\underline{\text { barns }}\end{array}$ & $\begin{array}{l}\text { Weight of } \\
\mathrm{U}^{238}, \mathrm{gm} \\
\end{array}$ & $\begin{array}{l}\sqrt{\mathrm{S} / \mathrm{M}} \\
\mathrm{cm} / \mathrm{g}^{\frac{1}{2}} \\
\end{array}$ \\
\hline I & $\begin{array}{l}\mathrm{A} \\
\mathrm{B}\end{array}$ & $\begin{array}{l}\text { Uranyl N1trate } \\
\text { On Paper }\end{array}$ & & $\begin{array}{l}277 \pm 3 \\
278 \pm 3\end{array}$ & $\begin{array}{l}0.000063 \\
0.000063\end{array}$ & $\begin{array}{l}200 \\
200\end{array}$ \\
\hline II & $\begin{array}{l}\text { A } \\
\mathrm{A} \\
\mathrm{B} \\
\mathrm{B}\end{array}$ & Metal $\mathrm{U}^{238}$ & $\begin{array}{l}1.939 \\
1.893 \\
1.770 \\
1.735\end{array}$ & $\begin{array}{l}44.5 \pm 1.5 \\
46.7 \pm 1.5 \\
58.0 \pm 1.8 \\
60.6 \pm 1.8\end{array}$ & $\begin{array}{l}1.230 \\
1.138 \\
0.608 \\
0.580\end{array}$ & $\begin{array}{l}1.54 \\
1.59 \\
2.12 \\
2.16\end{array}$ \\
\hline 111 & $\begin{array}{l}\text { A } \\
\mathrm{A} \\
\mathrm{A} \\
\mathrm{B} \\
\mathrm{B} \\
\mathrm{B}\end{array}$ & Metal U $\mathrm{U}^{238}$ & $\begin{array}{l}1.349 \\
1.343 \\
1.570 \\
1.759 \\
1.731 \\
1.573\end{array}$ & $\begin{array}{l}117 \pm 2 \\
119 \pm 2 \\
72.2 \pm 1.8 \\
58.8 \pm 2.0 \\
61.0 \pm ? .0 \\
77.4 \pm 2.0\end{array}$ & & $\begin{array}{l}4.52 \\
4.52 \\
2.73 \\
2.10 \\
2.18 \\
2.73\end{array}$ \\
\hline IV & $\begin{array}{l}\text { A } \\
A \\
B \\
B \\
B\end{array}$ & 16 wt $\% \mathrm{U}^{238}$ in $\mathrm{Al}$ & $\begin{array}{l}1.185 \\
1.172 \\
1.201 \\
1.215 \\
1.196\end{array}$ & $\begin{array}{l}221 \pm 5 \\
238 \pm 5 \\
220 \pm 5 \\
206 \pm 5 \\
228 \pm 5\end{array}$ & $\begin{array}{l}0.0220 \\
0.0119 \\
0.0250 \\
0.0376 \\
0.0198\end{array}$ & $\begin{array}{l}11.1 \\
14.7 \\
10.5 \\
9.11 \\
11.7\end{array}$ \\
\hline $\mathrm{V}$ & $\begin{array}{l}\text { A } \\
\text { A } \\
\text { A } \\
\text { A } \\
\text { B } \\
\text { B } \\
\text { B } \\
\text { B }\end{array}$ & 16 wt $\% U^{238}$ in $A 1$ & $\begin{array}{l}1.150 \\
1.152 \\
1.153 \\
1.150 \\
1.162 \\
1.181 \\
1.159 \\
1.157\end{array}$ & $\begin{array}{l}273 \pm 7 \\
269 \pm 7 \\
267 \pm 7 \\
273 \pm 7 \\
273 \pm 7 \\
274 \pm 6 \\
278 \pm 7 \\
281 \pm 7\end{array}$ & $\begin{array}{l}0.00227 \\
0.00315 \\
0.00500 \\
0.00258 \\
0.00194 \\
0.01140 \\
0.00179 \\
0.00186\end{array}$ & $\begin{array}{l}33.5 \\
27.3 \\
22.5 \\
31.5 \\
35.8 \\
15.2 \\
37.4 \\
36.8\end{array}$ \\
\hline $\mathrm{VI}(\mathrm{c})$ & $\begin{array}{l}\text { A } \\
\text { A } \\
\text { A } \\
\text { A } \\
B \\
B \\
B \\
B\end{array}$ & 16 wt $\% \mathrm{U}^{238}$ in $\mathrm{Al}$ & $\begin{array}{l}1.200 \\
1.199 \\
1.228 \\
1.254 \\
1.209 \\
1.243 \\
1.239 \\
1.268\end{array}$ & $\begin{array}{l}205 \pm 5 \\
206 \pm 5 \\
180 \pm 6 \\
160 \pm 6 \\
211 \pm 5 \\
182 \pm 6 \\
185 \pm 6 \\
164 \pm 6\end{array}$ & $\begin{array}{l}0.0263 \\
0.0263 \\
0.0526 \\
0.0789 \\
0.0263 \\
0.0526 \\
0.0526 \\
0.0789\end{array}$ & $\begin{array}{r}10.3 \\
10.3 \\
7.62 \\
6.39 \\
10.30 \\
7.62 \\
7.62 \\
6.39\end{array}$ \\
\hline
\end{tabular}

(a) See Figure 1.

(b) Based on $8 \sigma_{\text {th }}=2.73$ barns.

(c) The folls in this set were 0.020 -inch-thick nominal and were 0.51 inch in diameter, and consisted of a single foll, or two or three in a.stack. See text for a discussion of cadmium covers for the foll stacks. 
unresolved resonances and the nonresonant absorption. The relatively small thermal flux depression for the se captures becomes important only for the thick folls (Iow $S / M$ values). At the lower values of $S / M$, it is of interest to compare the present experimental results w1th previous measurements on strongly absorbing rods. What are belleved to be the most accurate measurements on such rods were those made by Hellstrand $(26)$. For values of the total resonance integral including a $1 / \mathrm{v}$ component of 1.10 barns Hellstrand gives

$$
R I=4.05+25.8 \sqrt{S / M}
$$

This expression is shown plotted in Figure 5. Although based on measurements at $\sqrt{\mathrm{S} / \mathrm{M}}$ values below 1.0 , his curve is seen to f1t the data of the present experiment over a wide range. In particular the values for the thickest folls are seen to lie precisely on his curve.

The calculated value of the resonance flux depression expected for cylludelual semetry id aloo shown by the dashed curve of Figure 5. For reactor lattices it is normally assumed that the resonance integral as given by Equation 11 applies equally to rods, tubes, and plates. The curves of Figure 5 show that this is Justified for resonance integrals below 50 barns where the two curves colncide. The distinction between the two geometries is, however, seen to be appreclable for higher values of the resonance integral.

The thickest folls of the uranium aluminum alloy folls (Experiment VI of Table VI) required special consideration. The stacks of three 0.020-1nch-thick folls, the 0.0789-gm folls of Table VI, were too thick to permit normal closing of the cadmlum plilbox. For these folls an add1tional sheet of 0.010-inch-thick cadmium was wrapped on the edges of the pillboxes. The change of shadow shielding due to the increased size of the cadmium pillboxes is negligible, but changes in the thermal neutron diftusion depressions in the vicinity of the cavity may introduce small systematic errors. An estimate of this effect is included in the experimerilal uncertainties. In addition, for the thickest uranium-iluminum folls, a correction is necessary for the effect of energy exchange by scattering in aluminum within the foil. In order to estimate the magnitude of this effect, the narrow resonance approximation. was used, that is, the effective energy width of the resonance was taken to be small w1th respect to the maximum energy lost in an eldslic scattering of a neutron from an aluminum atom. The calculated correction reduces the resonance integral by $0.5 \%$ for the $0.0789-\mathrm{gm}$ fo1l stack and $0.2 \%$ for the $0.0526-\mathrm{gm}$ stack. The effect is therefore negligible for the thinner folls. 


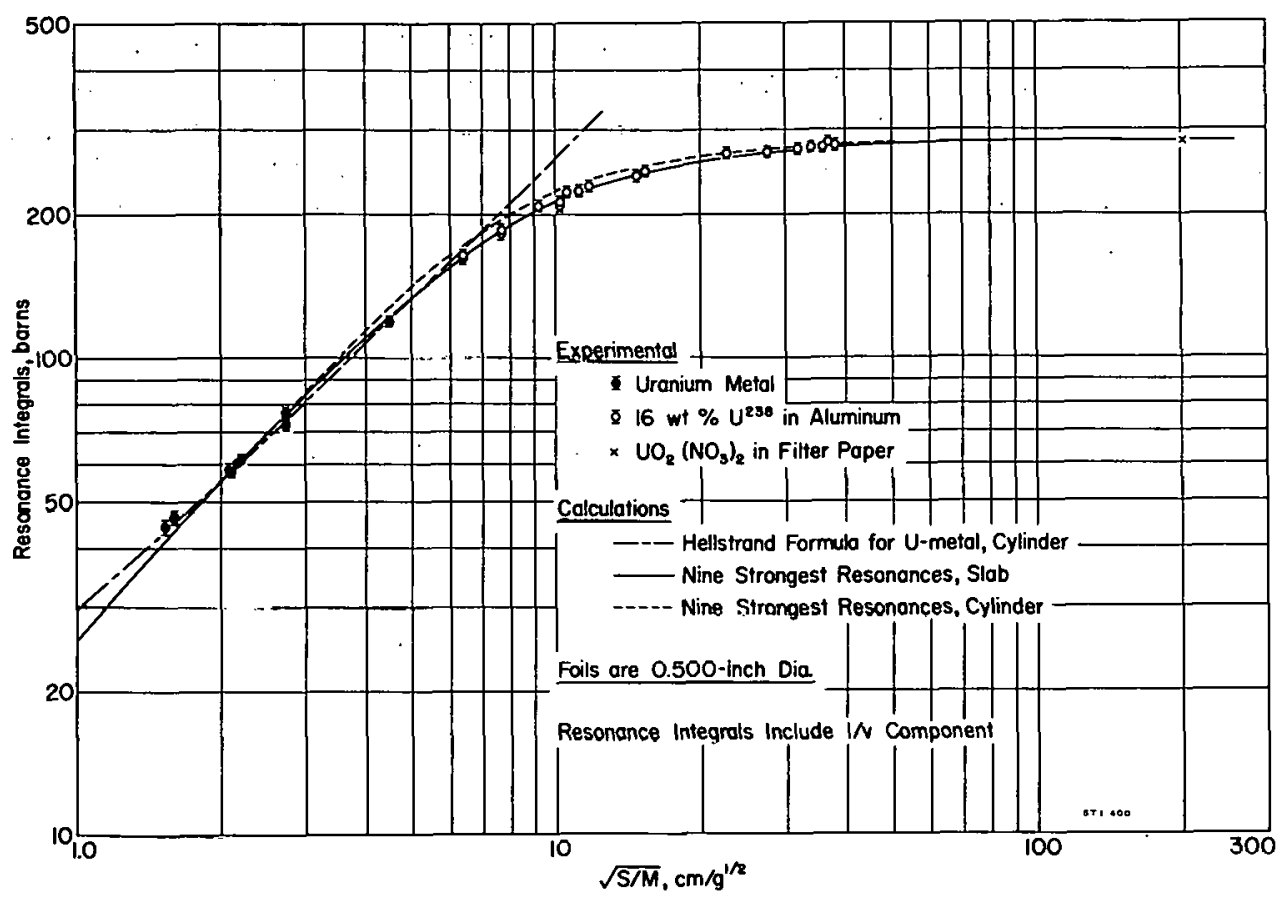

FIG. 5 EFFECTIVE RESONANCE CAPTURE INTEGRAL FOR U ${ }^{238}$ AS A FUNCTION OF FOHL THICKNESS (Ișotropic Flux in Cavity)

$\operatorname{In}^{115}$

The experimental determination of the resonance integral of In $^{115}$ has been re-evaluated from the earlier SRL data( $(9)$ on the basis of the present formalism and cross section values. Only the data for the central irradiation position of the earlier experiment were used. An inspection of the cadmium ratios taken at the two positions used in the earlier experiment indicated a systematic variation with resonance energy as one goes from indium (1.46 ev), to gold (4.9 ev), to tungsten (18.8 ev): This systematic variation is most readily explained by assuming that the epithermal flux deviates from a $1 / E$ dependence for the outermost position, 24 inches. from the center of the SP.

Another complication in interpreting the earlier experiments arises because about $80 \%$ of the neutron captures In $\operatorname{In}^{115}$ lead to an isomeric state of $\operatorname{In}^{116}$ which decajo with a 54-minute half-life by $\beta, \gamma$ emission to the ground state of $\mathrm{Sn}^{116}$, and the remalning $20 \%$ lead to the ground state of $\operatorname{In}^{116}$ which decays w1th a 13-second half-l1fe by means of a 3-Mev $\beta$ particle directly to the ground state of $\mathrm{Sn}^{116}$. Although the branching ratio of the two alternatives is known (1) for thermal neutron capture, it could not be determined from the Iiterature if the ratio was different for epicadmium captures. To determine this relation an 
experiment was devised to compare cadmium ratios of the 13-second act1vity to that of the 54-minute act1vity for a range of foll thicknesses. The cadmium ratios for the 13-second activities were measured with high precision by the method given in Appendix $\mathrm{C}$. The results of the measurement are shown in Table VIII.

\section{TABLE VIII.}

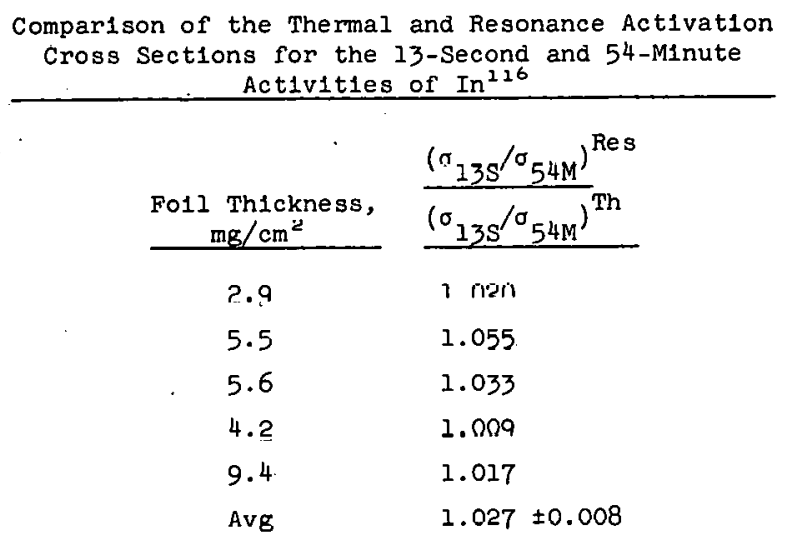

Since no systematic variation with thickness was observed, the average value of the activation ratio was used.

The following relations were used in the re-evaluation of the earlier measurements on the In $^{115}$ resonance integrals.

$$
R I^{54 \dot{M}}=\frac{R I^{A u}}{\left(g \sigma_{t h}\right)} F\left(g \sigma_{t h}\right)^{54 M} \frac{[f(C R)-I]^{A u}}{[f(C R)-1]^{54 M}}
$$

$$
R I^{13 S}=\frac{R I A u}{\left(g \sigma_{t h}\right)^{A u}} F\left(g \sigma_{t h}\right)^{13 S} \frac{\left(\sigma_{13 S} / \sigma_{54 M}\right)^{R e s}}{\left(\sigma_{13 S} / \sigma_{54 M}\right)^{T h}} \frac{[f(C R)-1]^{A u}}{[f(C R)-1]^{54 M}}
$$

The following cross sections and measured values were used: $\mathrm{RI}^{\mathrm{Au}}$, 1530 barns; ( $\left.\mathrm{g} \sigma_{\mathrm{th}}\right)^{\mathrm{Au}}, 99.4$ barns; $\left(\mathrm{g} \sigma_{\mathrm{th}}\right)^{54 \mathrm{M}}, 156$ barns; $\left(g \sigma_{t h}\right)^{13 S}, 38.7$ harns; $f^{A u}, 0.985 ; f^{I n}, 0.937^{(\operatorname{Ref} .8)}$; $(\mathrm{CR})^{\mathrm{Au}}, 2.20 ;(\mathrm{CR})^{54 \mathrm{M}}, 2.26$; and the activation cross section ratios from Table VIII. The factor $F$ takes into account the deviation. from. $I / v$ of the indium absorption cross section in the epithermal-subcadmium energy interval. Its value was determined by numerical integration and was determined to be 1.017 for the experlmental flux spectrum. The resultant integrals, including the $1 / \mathrm{v}$ component, are $2550 \pm 80$ barns for the $54 \mathrm{M}$ activity and $650 \pm 30$ barns for the $13 \mathrm{~S}$ activity, or a total activation integral of $3200 \pm 100$ barns. 
The exact calculation of the eplcadmium resonance integral is very laborious for a material such as indium where the wing of the resonance extends into the subcadmium region. It can quite readily be approximated, however, by calculating the entire resonance integral by means of Equation 10 for each of the resonances and subtracting from this quantity the excess of the resonance integral over the $1 / v$ component in the subcadmium region. This latter value was obtained by numerical integration to give a calculated value of 3190 barns for all resolved resonances and the $1 / \mathrm{v}$ component for a cadmium cutoff energy of $0.622 \mathrm{ev}$. Th1s compares with the value of 3213 barns given by $\operatorname{Kelber}^{(27)}$, and the measured value of $3200 \pm 100$ barns.

Flux depression factors were calculated for indium by the same procedure as for gold. Only the three lowest resonances contribute perceptibly to the flux depression factor for the foll thicknesses used. The eplcadmium $1 / \mathrm{v}$ component was not considered separately since its resonance integral lies chiefly under the $1.46-e v$ resonance. The thermal flux depression factors were calculated with a thermal cross section value, $\sigma_{\text {th }}$, of 191 barns. The results of the computations are given in Table IX and are compared to the earlier SRL measurements $(9)$ in Figure 6. The agreement is seen to be very good over the entire thickness range. The results of Table IX also agree closely w1th measurements of the resonance flux depression for indium given by Trubey ${ }^{(28)}$.

TABLE IX

Computed Resonance and Thermal Depression Factors for In ${ }^{i 15}$ Activations in an Isotropic Flux in a Cavity

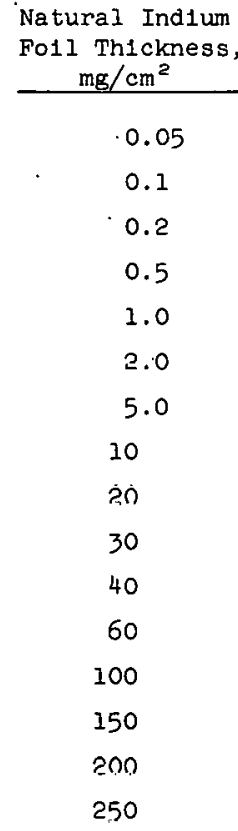

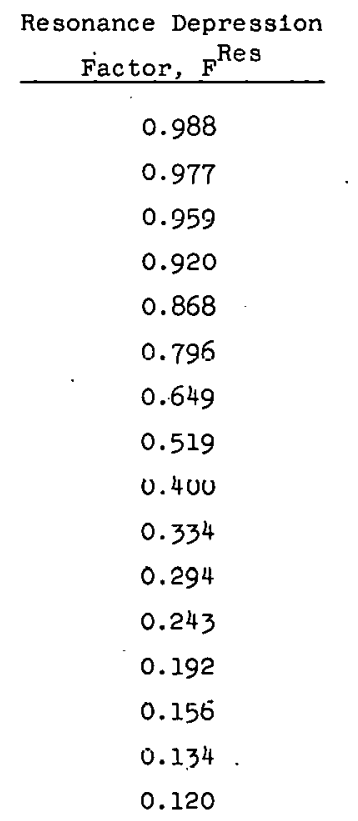

\begin{tabular}{cc}
$\begin{array}{c}\text { Thermal Depression } \\
\text { Factor, F }\end{array}$ & $\mathrm{F}^{\text {Res }} \mathrm{F}^{\text {th }}$ \\
\hline 1.000 & 0.988 \\
1.000 & 0.977 \\
0.999 & 0.960 \\
0.998 & 0.922 \\
0.997 & 0.870 \\
0.993 & 0.801 \\
0.987 & 0.658 \\
0.976 & 0.531 \\
0.956 & 0.417 \\
0.939 & 0.357 \\
0.924 & 0.319 \\
0.897 & 0.211 \\
0.850 & 0.226 \\
0.800 & 0.195 \\
0.759 & 0.177 \\
0.720 & 0.167
\end{tabular}




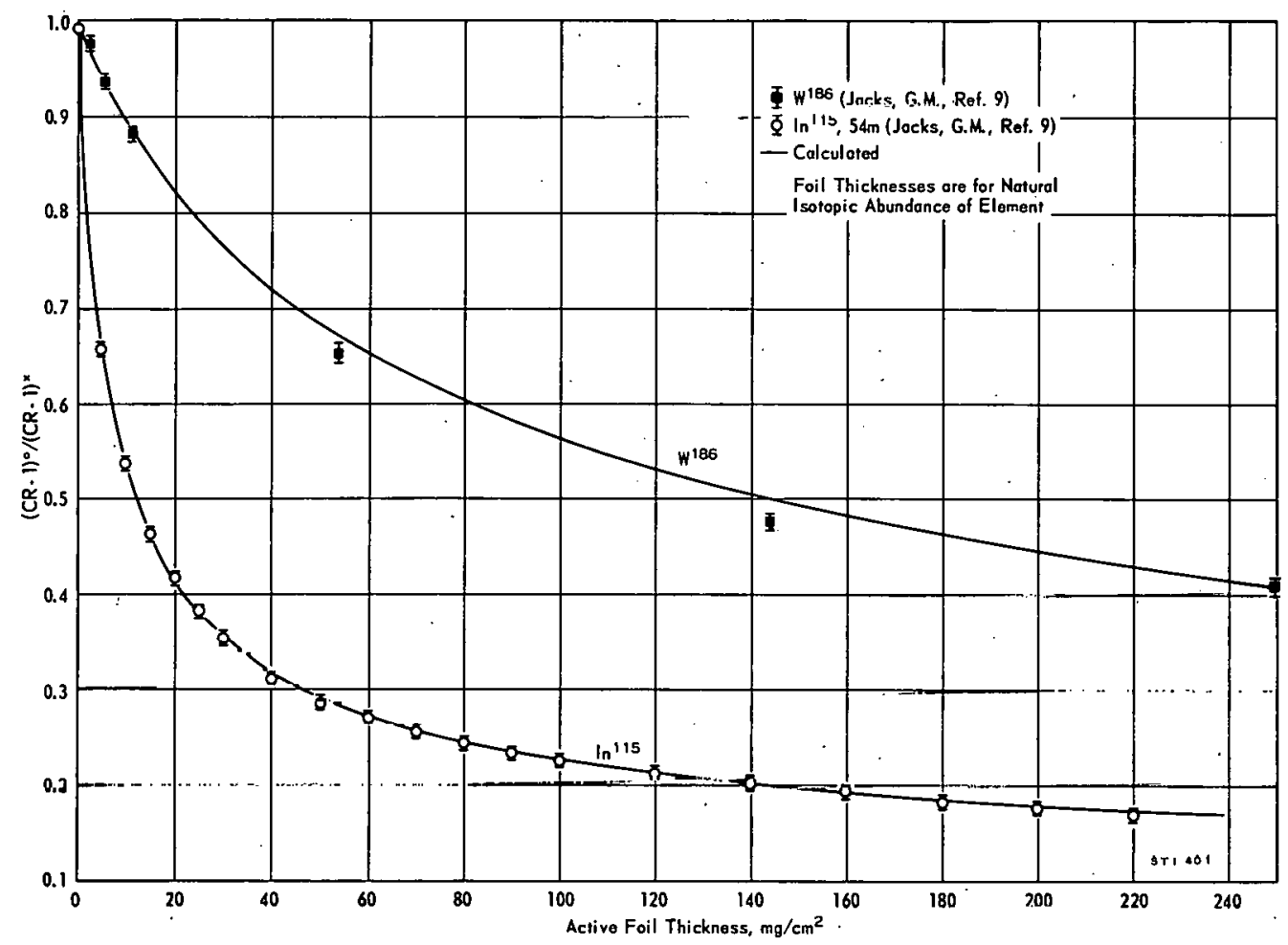

FIG. 6 THICKNESS CORRECTIONS FOR CADMIUM RATIOS OF $\ln ^{115}$ AND $W^{186}$ FOILS (Isotropic Flux in Cavity)

$W^{186}$

New activation measurements were made on thin tungsten foils, and the earlier measurements $(9)$ were re-evaluated on the basis of the present f'ormallsm and cross sections. The calculated curve for the flux depression factors is shown In Figure 6 where it is compared to the earlier measurements. The agreement is seen to be good for all but the two intermediate foil thicknesses. Although the discrepancy may be due to an error in the experiments, it is more likely due to the neglect of resonance soattering in the calculation. The ratio of resonance scattering to resonance absorption is much greater than for indium, gold, and $U^{238}$, for which the agreement was found to be good. The inclusion of scattering would tend to lower the calculated curve. A similar discrepancy, but of even greater magnitude, has been reported by other observers $(29)$.

The previously reported resonance integral(9) of $\mathrm{W}^{186}$ has also been re-evaluated. The calculated correction curve of Figure 2 gives an average value of 2.53 for the cadmium ratio of zero thickness $W^{186}$ at the central position as determined from the three thinnest foll palrs. (For the reasons discussed in the section on indium, the 24-inch position was ignored.) Using a thermal cross section for $\mathrm{W}^{186}$ of 
$35 \pm 3$ barns $(1)$ and making the comparison to the gold cadmium ratio for this location, one obtains a value for the measured resonance integral of $410 \pm 40$ barns, including the 14-barn $1 / v$ component. Calculations from the resonance parameters $(1)$ for the three strongest resonances by Equation 10 glves a corresponding value of $464 \pm 56$ barns. Assuming only the 18.8 -ev resonance, Equation 9 gives a value of $486 \pm 54$ barns which becomes $500 \pm 54$ barns when the $1 / v$ component is included.

Although the discrepancy between calculations and the measured resonance integral are within the comblned errors, an investigation was made of possible sources of experimental error. This investigation disclosed that shielding by cadmium could give an erroneously low value for the measured integral. Tabulated resonance parameters ${ }^{(1)}$ show that cadmlum has a resonance at $18.5 \pm 0.2$ ev which partially overlaps and shields the tungsten resonance at $18.8 \pm 0.2 \mathrm{ev}$. Various methods are available for experimentally determining such shielding effects. The method of varying the cadmium thickness ${ }^{(8)}$ used for gold and indium does not work for overlapping resonances. One method, not used in the present work, is to pair the tungsten folls with folls of a material such as copper for which there is no shlelding by cadmium. Normalizations for this method are made by simultaneous activations obtained for the two foll materials in a completely thermalized flux. Another method, the one used here, is to substitute a different filter material for the cadmium, one for which the shielding is negligible or readily calculable. Gadolinium and samarium, which would normally be the best replacements for cadmium, also have resonances nedr $10.0 \mathrm{ev,} 30$ boron was user.

The boron filters used were determined to have an effective $\mathrm{B}^{10}$ thickness of $9.1 \mathrm{mg} / \mathrm{cm}^{2}$ by means of the experiment described in Appendix $D$. The tungsten folls consisted of $5 \mathrm{wt} \% \mathrm{WO}_{3}$ dispersed in aluminum at an average turigs leil density of $3.0 \mathrm{mg} / \mathrm{cm}^{2}$, Cadmium ratios and analogous boron ratios were obtained by the usual irradiation in the $\mathrm{SP}$. The measured geometric mean ratios (from reversing bare and covered folls) were 2.49 for cadmium and 2.83 for boron at "A" position of Figure 1. The measured cadmium ratio used In Equation 8, assuming no resonance shielding, gave a value of $380 \pm 40$ barns including the $1 / \mathrm{v}$ component based on $\sigma_{\text {th }}=35 \pm 3$ barns. The calculated correction to zero thickness gives a corresponding integral of $394 \pm 40$ barns. The boron cadmium ratio was converted to an 1deal1zed unshielded cadmium ratio by the following computed transmission factors: 18.8-ev resonance, 0.76; eplcadmium 1/v, 0.1; thermal, 0.030. These depression. factors give an equivalent 1deallzed cadmium rat1o of 2.20 , and by means of Equation 8 , 
a value for the resonance integral of 473 barns for the. actual foll thickness. Correcting to zero thickness gives a value of $490 \pm 50$ barns including the 14 -barn $1 \% \mathrm{v}$ component. Comparison of 1dealized cadmium ratio to the measured one gives a resonance shlelding factor of 0.885 . Use of this shielding factor in the earlier measurements (19) gives a resonance integral of $506 \pm 50$ barns including the $1 / \mathrm{v}$ component. This value agrees reasonably well with the present measurement and with the calculated values.

\section{NEUTRON SPECTRUM IN THE SP}

The results of the present experiment strongly support the validity of the assumption of a $1 / E$ epithermal flux at the certer of the SP. The resonance integrals derived under this assumption show good agreement with measurements taken at other facilities. where direct measurements of the spectrum were made $(7,14)$ or where pelidule epectrum:calculations could be made ${ }^{(22)}$. The agreement holds from 1.46 ev for indium to $2.85 \mathrm{Kev}$ for sodium and also for $\mathrm{U}^{235}$ and $\mathrm{U}^{238}$, which have many resonances distributed over the entire energy range. Such agreement would be most unlikely if there were appreciable deviation from a $I / E$ spectrum in the SP. Measurements at the center of the TTR ${ }^{(11)}$, a facility nearly 1dentical to the SP, also support the assumption.

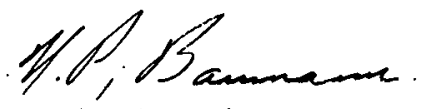

N. P. Baumann.

Experimental Phyolcs Division. 


\section{APPENDIX A}

\section{CALCULATION OF FLUX DEPRESSION FACTORS}

THERMAL

Thermal flux depression factors are calculated w1th Maxwellian-averaged cross sections in the monoenerget1c approximation. Here flux depression factors are defined as the ratio of the activity per unit mass of a thick foli to that which an infinitely thin foil of the same material would have had under identical irradiation condition. For an isotropic and monoenergetic neutron flux incldent on a slab absorber within a cavity, the average flux depression within the slab is given by the following relation.

$$
f_{s l a b}=\frac{1-2 E_{3}(x)}{2 x}
$$

Here $X=N \sigma_{a}$ where $N$ is the atom density of the foll per unit area and $\sigma_{\mathrm{d}}$ lis the microscopic absorption cross section per atom. The $\mathrm{E}_{3}$ function is the exponential integral over the incldent angles discussed in Appendix D. Numerical values for this function are tabulated by Case $(30)$, et al. Equation 1 is strictly true only for pure absorption; however, the error introduced by neglecting scattering is appreciable only if the scattering cross section is much larger than the absorption cross section. A plot is given in Figure 7 for use in calculating thermal flux depression factors.

\section{EPITHERMAL $1 / \mathrm{v}$}

The monoenergetic depresision factor, $f_{\mathrm{slab}}$, of Equation 1 applies at each energy if $\sigma_{a}$ varles with energy. For a foll of given thickness the activity of a detector foll, with an activation cross section $\sigma_{a}(E)$ in an isotropic flux $\phi(E)$, relative to that for an infinitely thin foll in the same flux is given by

$$
\mathbf{f}=\int \dot{f}(N, E) \sigma_{a}(E) \phi(E) d E / \int \sigma_{a}(E) \phi(E) d E
$$

where $f(N, E)$ is given by Equation 1 . Equation 2 has been evaluated for a $1 / v$ cross section in a $1 / E$ flux between the limits of $E_{c}$ and $\infty$. The resultant curve is shown in Figure 7 , where the parameter $\mathrm{X}=\mathrm{N} \sigma\left(E_{\mathrm{c}}\right)$. Here $\mathrm{N}$ is in the atom density per unit area and $\sigma\left(E_{c}\right)$ is the absorption cross section value at the lower energy limit $E_{c}$. The total epicadmium depression is obtained by letting $F_{c}$ be equal to the effective cadmium cutoff energy. The curve of Figure 7 may also be used to 
determine the depression factor for a finite energy interval such as the epithermal subcadmium region. This is accomplished by noting that the depression factors weighted by their respective dilute resonance integrals are additive.

RESONANCE FLUX

\section{Beam Flux, No Doppler Broadening}

The problem of the flux depression in an absorbing slab has been solved analytically for a single Breit-Wigner resonance in the absorber with a beam flux at normal incidence to the slab surface $(27,31)$. A flux constant with energy is assumed. Consider a slab of total thickness $X$ with $N(X)$ atoms per unit area. At a distance $x_{O}$ from the front face, w1th $N\left(x_{O}\right)$ atoms per mith area between that point and tho front facc, the depression at that point is given by

$$
\begin{aligned}
r\left(X_{0}\right) & =e^{-\left(X_{0} / 2\right)} I_{0}\left(x_{0} / 2\right) \\
X_{0} & =N\left(X_{0}\right) \sigma_{a}^{\max } \\
\sigma_{a}^{\max } & =\frac{2.6036 \times 10^{6}}{E_{0}} \frac{\Gamma_{n} \Gamma_{\gamma}}{\Gamma^{2}}
\end{aligned}
$$

where $I_{0}$ is a modified Bessel function of the flrst kind. This function is frequently designated as a Bessel function with an Imaginary argument $(32)$ as $J_{0}(1 x)$. The average depression over the whole foil is obtained by averaging Equation 3 over the total foil thickness. The rosult is

$$
\begin{gathered}
f(x)=e^{-(x / 2)} \cdot\left[I_{0}(x / 2)+I_{1}(x / 2)\right] \\
X=N(X) \sigma_{a}^{\max }
\end{gathered}
$$

where $I_{1}$ is also a modified Bessel function of the first kind and is frequently designated $(32)$ as $-1 J_{1}(1 x)$. The flux depression factors obtained from Equation 6 are plotted in Figures 7 and 8 .

\section{Isotropic Flux, No Doppler Broadening}

The flux depression for isotroplc flux incidence is complicated by the integration over angles. Such computations have been performed numericaliy(27). Useful approximations are available(27) in terms of the effective foll thickness 


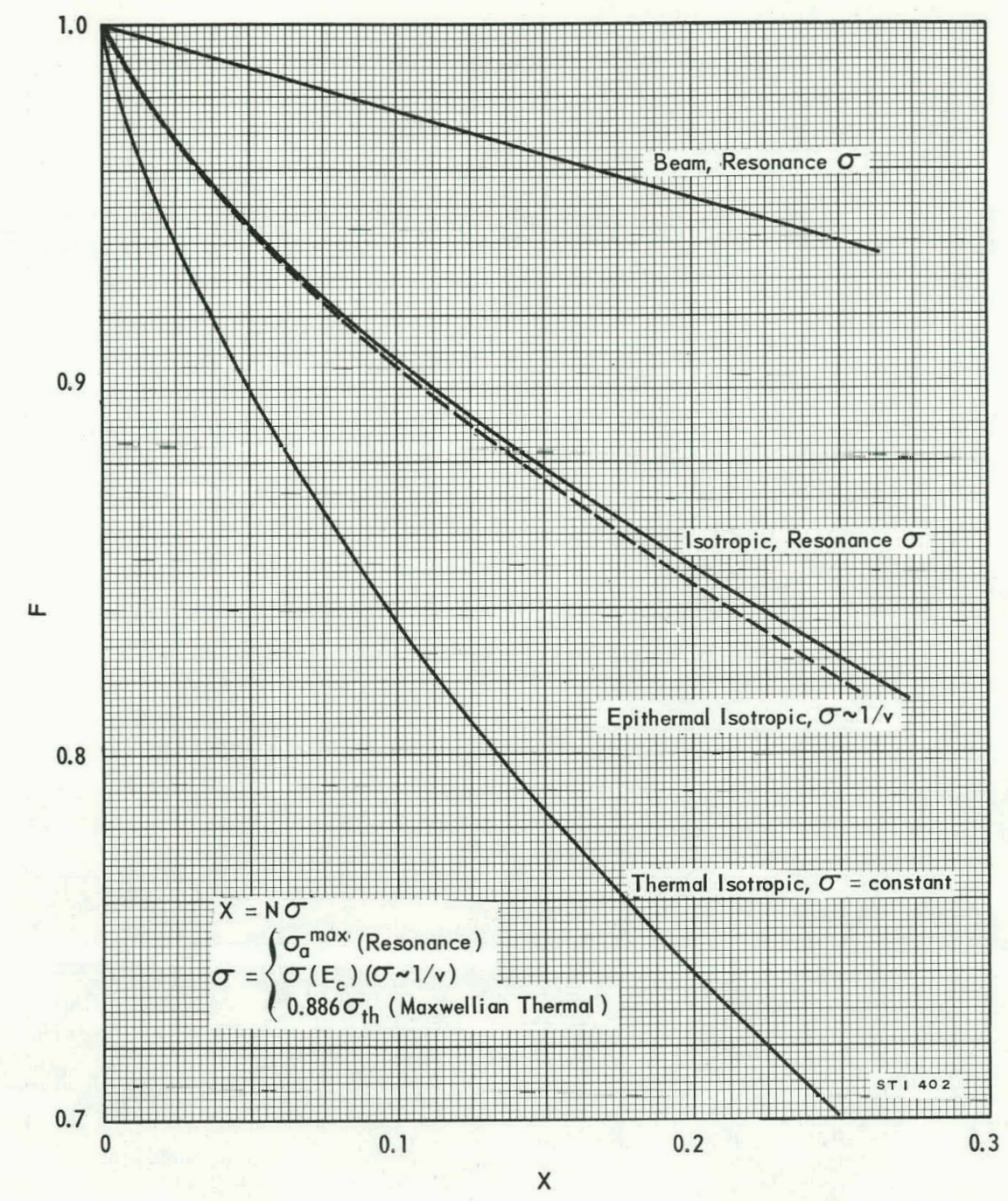

FIG. 7 FLUX DEPRESSION FACTORS FOR THIN FOILS WITH NO DOPPLER BROADENING 


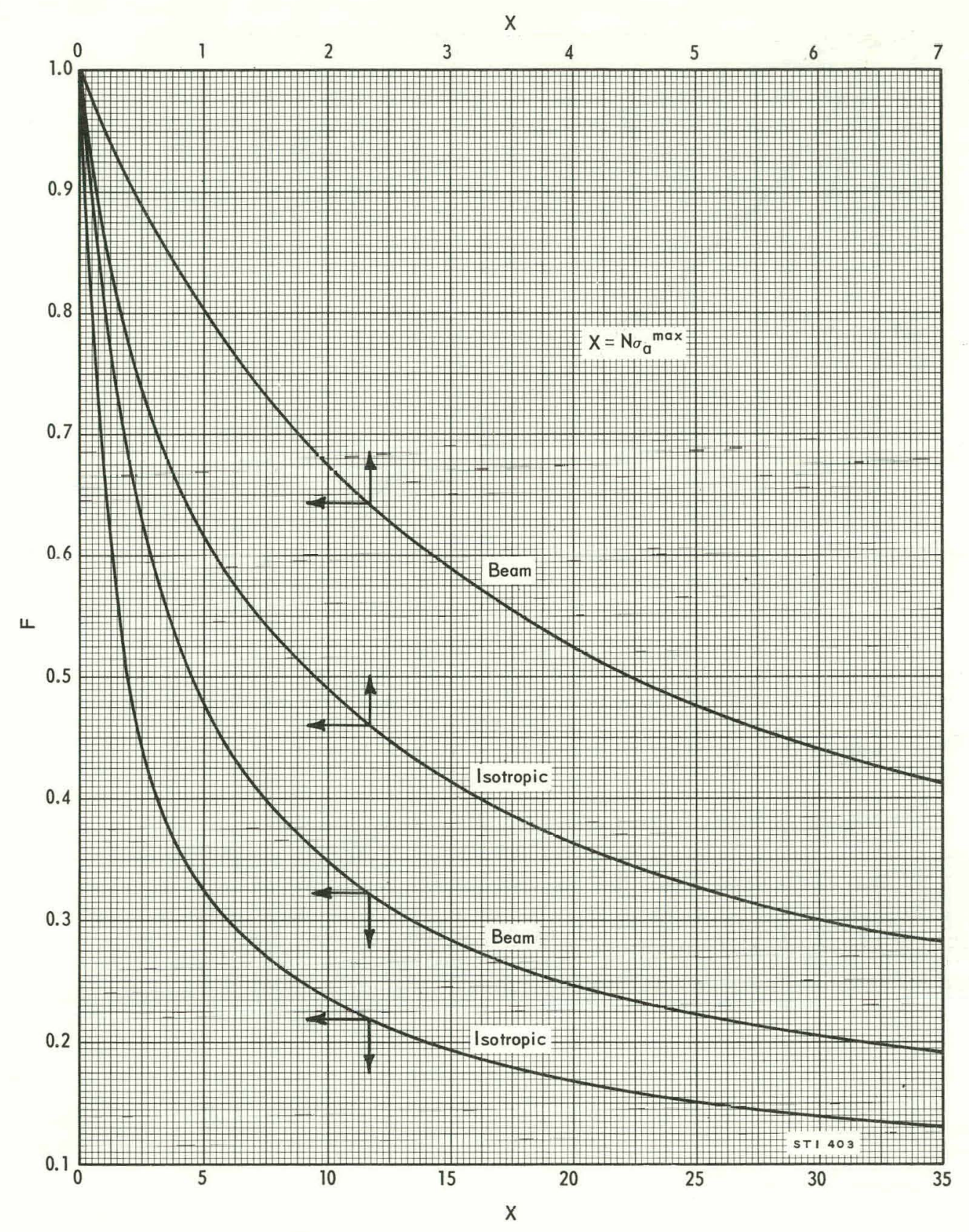

FIG. 8 RESONANCE FLUX DEPRESSION FACTORS FOR THICK FOILS WITH NO DOPPLER BROADENING 
$\mathrm{X}=\mathrm{N} \sigma_{a}^{\max }$, for very thin or very thick foils.

$$
\begin{array}{ll}
f(x) \cong 1+\frac{X \ln X}{4}-0.3274 x & x<<1 \\
f(X) \cong 1.3333(\pi X)^{-\frac{1}{2}} & x>1
\end{array}
$$

The calculated depresion factors are shown in Figures 7 and 8.

\section{Isotropic Flux with Doppler Broadening}

Tabulated resonance parameters are given in terms of the relative motion of the neutron and target atom. When it is desired to make calculations in terms of the neutron energy alone, some corrections must be introduced for any motion of the target atoms. Ordinarily this is thermal motion with a Maxwellian velocity distribution isotropic in direction. Here the correction serves to broaden the width and reduce the maximum cross section of the Breit-Wigner resonance. Solutions of the Doppler broadening problem have been obtained in various approximations $(5,6)$. For the present purpose, the results of computations performed by Roe ${ }^{(33)}$ as presented by Stewart and Zweifel(6) appear the most suitable. They express these results in terms of the parameter $\tau$, where

$$
\tau=\frac{2 \mathrm{~V}}{\mathrm{~S}} \mathrm{~N}_{\mathrm{a}} \sigma_{\mathrm{a}}^{\max }
$$

Here $V$ is the volume, and $S$ is the total surface area of the absorbing material, $\mathrm{N}_{a}$ is the volume density of absorber atoms, and $\sigma_{a}^{\max }$ the peak resonance absorption cross section. For an infinite $\mathrm{slab}, \tau=\mathrm{X}$ as defined in the preceding section. For foils with a non-negligible edge surface, the more general form is used. With Doppler broadening, the depression factor cannot be calculated from $\tau$ alone. The added complexity may be expressed in terms of the single parameter $\theta$,

$$
\theta=\frac{4 E_{t h} E_{0}}{A \Gamma^{2}}
$$

where $E_{t h}$ is the temperature of the absorber in units of electron volts, $E_{O}$ is the resonance energy, $A$ is the ratio of absorber to neutron masses, and $\Gamma$ is the total reaction width of the resonance. The results for slab geometries are reproduced in Figures 9 and 10. Note that for $\theta=0$, these curves coincide with the appropriate curves in Figures 7 and 8. Curves have also been computed for resonance flux depressions in cylinders and spheres with Doppler broadening included(33,6). 


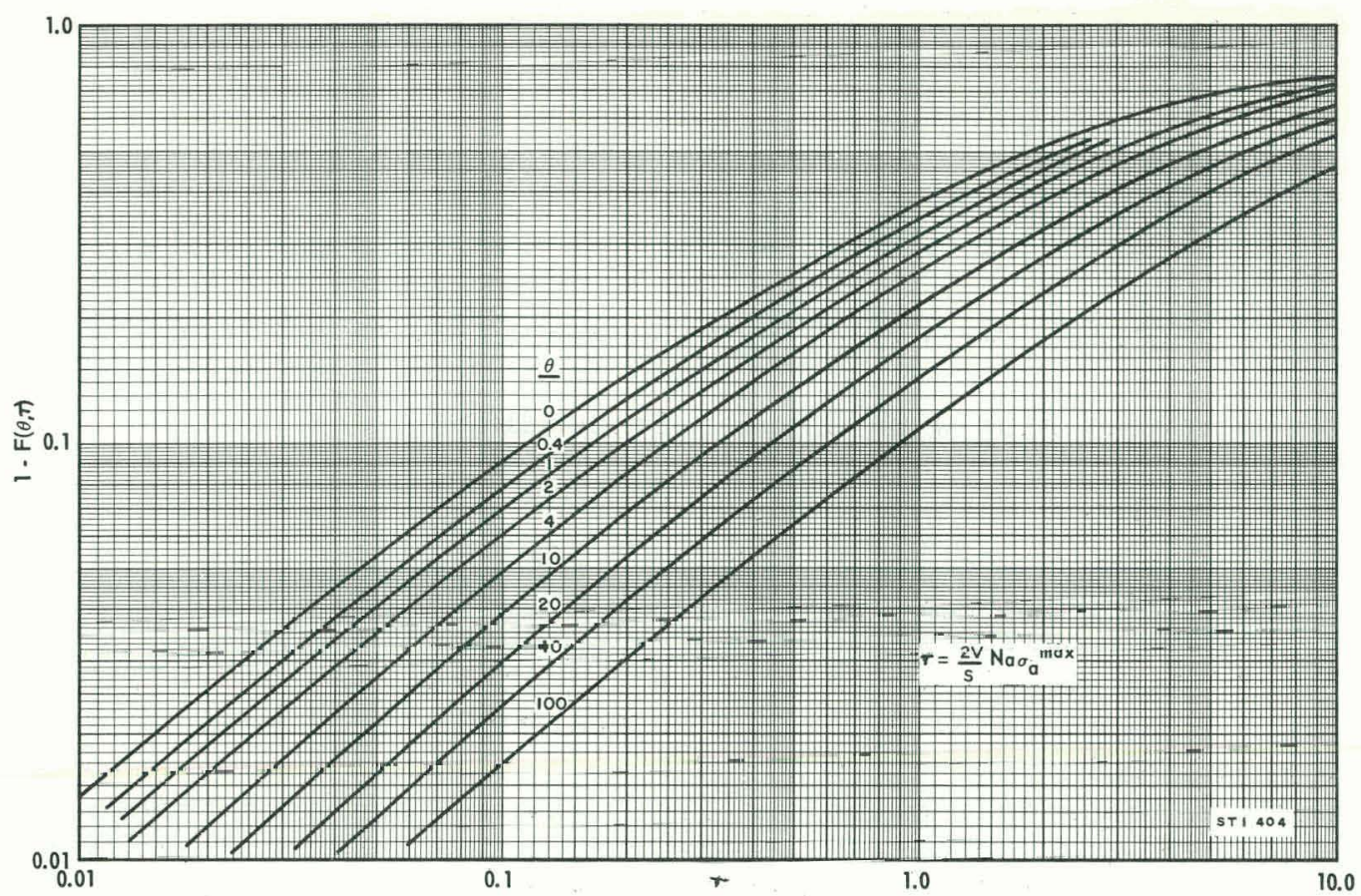

FIG. 9 RESONANCE FLUX DEPRESSION FACTORS FOR THIN FOILS WITH DOPPLER BROADENING INCLUDED

(From Roe, Ref. 33, and Stewart and Zweifel, Ref. 6)

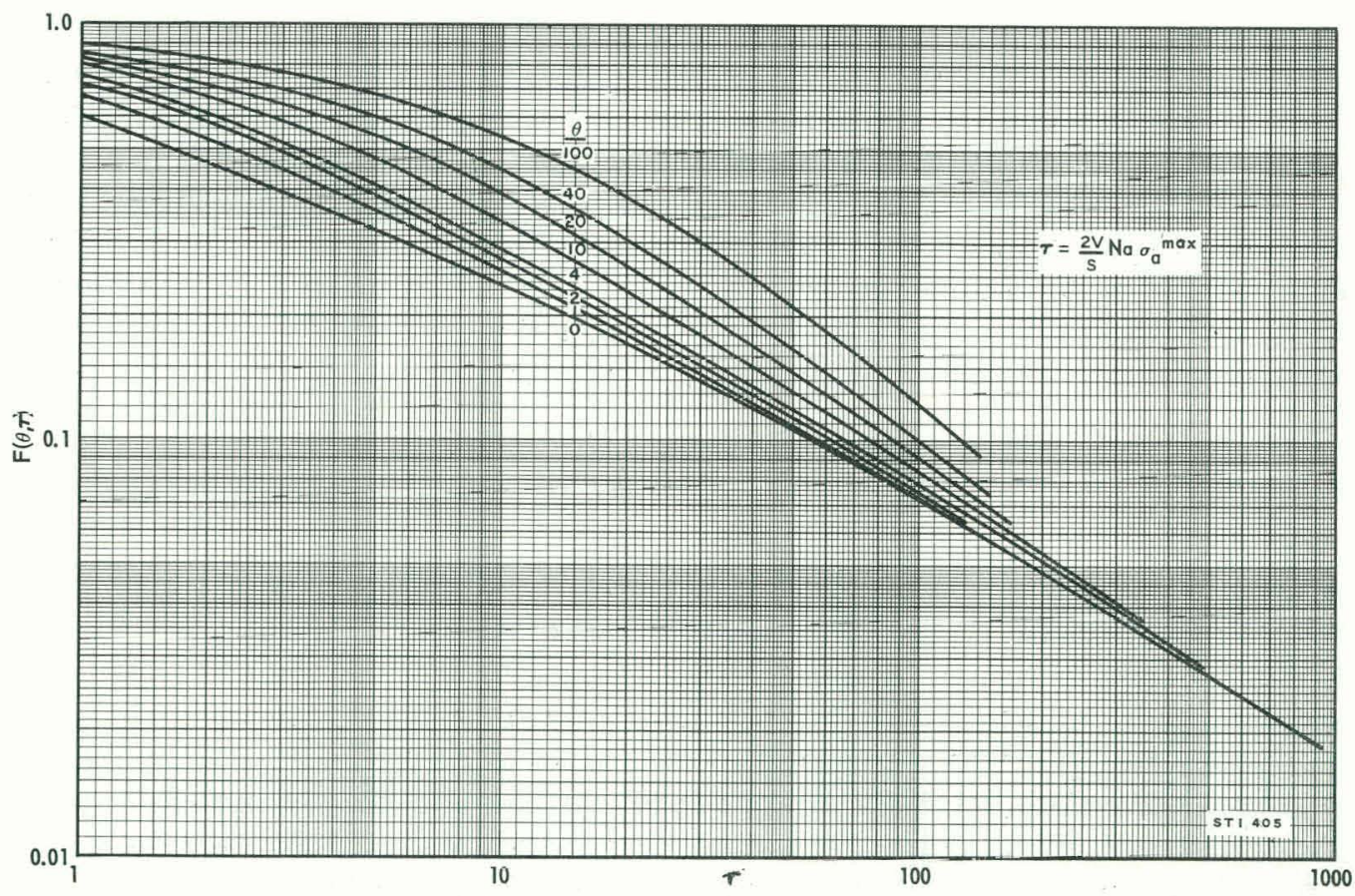

FIG. 10 RESONANCE FLUX DEPRESSION FACTORS FOR THICK FOILS WITH DOPPLER BRC:ADENING INCLUDED

(From Roe, Ref. 33, and Stewart and Zweifel, Ref. 6) 


\section{PAGES 43 to 44 WERE INTENTIONALLY LEFT BLANK}


When the product of the ratios of measured activities is taken, the time factors, $f$, and the efficiencies cancel out exactly and one has the following expression for the cadmium ratio.

$$
\left(\frac{A_{1} B_{2}}{A_{2} B_{1}}\right)^{\frac{1}{2}}=\frac{(\text { Act })_{\text {Bare }}^{\text {Sat }}}{(\text { Act })_{C d}^{\text {Sat }}} \equiv \operatorname{Cd~Rat10}
$$

This method has the advantage that neither the times, nor the time intervals need be known precisely. Simultaneity of time is all that is required. 


\section{APPENDIX D}

\section{DETERMINATION OF THE EFFECTIVE RESONANCE ENERGY FOR Mo 98 AND Mo 100}

For resonance detectors with one or two strong resonances, the energies of the resonances may be determined by 1rradiating a set of uniform foils of the detector material in a beam of epicadmium neutrons with varying thicknesses of $\mathrm{B}^{10}$ absorber materlal interposed between the folls and the neutron source. For a $1 / v$ absorber such as $B^{10}$, the effective absorber thickness, $Y=\left[N \sigma_{a}(E)\right]$, depends on the absorber atom density per unit area, $N$, and on the absorption cross section, $\sigma_{a}(E)$, which varies as $\mathrm{E}^{-\frac{1}{2}}$. For a single resonance the measured foil activations vary with absorber thickness as $\exp (-Y)$. Since the amount of boron and its thermal cross section are known, measurement of $Y$ uniquely determines the lesonanoe cnelugy. Under ineal oondllions of resunance strength and spacing, measurements can also be analyzed to obtain the energies of two or more resonances for a glven detector.

Epithermal beam fluxes of sufficlent strength to determine the resonance energy of $\mathrm{MO}^{98}$ were not avallable from the SP so a method was devised for making a similar analysis in an 1sotropic flux. Consider a detector foll whose effective absorption thickness is $X=N \sigma_{a}$, where $N$ and $\sigma_{a}$ now refer to the detector foll. The folls are encased in a plilbox of $\mathrm{B}^{10}$ absorber whose thickness on each face is $\mathrm{Y}$, defined as for the beam flux. At a given angle $\theta$ to the normal, the incident flux is attenuated by a factor exp $(-Y / \cos \theta)$ at the detector foll surface and the solld angle of the incldent flux is given by $2 \pi \sin \theta \mathrm{d} \theta$. The effective surface area normal to the direction of incidence is reduced by a factor of $\cos \theta$. The fraction of the neutrors reaching the detector f'oll which are absorbed in the foll 13 given by $[1-\exp (-X / \cos \theta)]$. Comblning the terms and cancelling out the constant factor, $2 \pi$, one obtains the following relation for the relative activity of an arbitrary thickness foll inside a variable thickness cover.

$$
\begin{aligned}
f(X, Y) & =\frac{\int_{0}^{\pi / 2} e^{-\frac{Y}{\cos \theta}} \cos \theta \sin \theta\left(1-e^{-\frac{X}{\cos \theta}}\right) d \theta}{\int_{0}^{\pi / 2} \cos \theta \sin \theta\left(1-e^{-\frac{X}{\cos \theta}}\right) d \theta} \\
& =\frac{2\left[E_{3}(Y)-E_{3}(X+Y)\right]}{1-2 E_{3}(X)}
\end{aligned}
$$


The $E$ functions are the exponential integrals which are tabulated by Case(30), et al. They are given analytically as

$$
E_{n}(X) \equiv \int_{0}^{\pi / 2} e^{-\frac{X}{\cos \theta}} \cos ^{n-2} \theta \sin \theta d \theta
$$

For resonances, Equation 1 depends sensitively on energy since $X$ is proportional to the foll cross section which varies strongly with energy at a resonance. The energy average over a resonance is in general a difficult problem. In the limiting case of an extremely thin foll, Equation 1 becomes $f(X, Y)=$ $E_{2}(Y)$ and in the limit of a thick (opaque). foll it becomes $f(X, Y)=2 E_{3}(Y)$. For a detector foll of intermediate thickness, a close approximation to the energy average of $\mathrm{X}$ is given by the constant value of $X$ which would give the same resonance self-shlelding for a bare foll. This value is obtained from Equation 1 of Appendix $A$ and the measured self-shielding f'actor.

For the measurement of the effective resonance energy for the molybdenum isotopes, absorbers were in the form of 18 wt $\% \mathrm{~B}^{10}$ in aluminum in sheets with a nominal thickness of 0.010 inch. The boron was in the form of finely ground boron powder granules dispersed in the aluminum matrix. The heterogeneous nature of the absorber foils necessitated the determination of the effective absorber thickness for each foll packet. For this purpose, gold folls of thickness $10 \mathrm{mg} / \mathrm{cm}^{2}$ and tungsten foils of thickness $52 \mathrm{mg} / \mathrm{cm}^{2}$ were placed adjacent to the molybdenum foils inside the absorber pillbox. The natural molybdenum folls had a thickness of $13.5 \mathrm{mg} / \mathrm{cm}^{2}(0.0005$ inch). The pillboxes were made from laminations of 0.625 -inch $D$ folls. A cavity for the stack. of detector folls was formed by removing an 0.500 -inch $D$ disc from the center of one of the larger boron-aluminum f'oils. Four, three, two, one, or no boron-aluminum folls were then placed on elther side of the detector folls. Ladmium discs 0.020 inch thick on both faces completed the cover packet. The irradiations were performed in the air-filled central cavity of the SP. The five foll packs were equally spaced on the rotating aluminum disc described earlier.

The activities of the detector folls were counted on sodium lodide scintillation counters. After correcting for minor variations in foll weights, the activity of each foil relative to the foll covered only by cadmium was determined. These activity ratios are shown in Figure 12. The gold foil activities were used to determine the effective thickness of the boron covers. The curve for the gold folls was calculated from Equation 1 with $X=0.30$. Additional curves for gold are 
shown in Figure 12 for the limiting cases of very thin and opaque folls to indicate the intermediate thickness of thie folis used. The measured gold activities were plotted on the calculated curve to give the effective boron cover thickness. As a check of the method, the measured $\mathrm{w}^{186}$ activities were compared to calculations. From Figure 12, the agreement is seen to be well within the experimental errors. The measured molybdenum activities do not agree for elther 1sotope. The most likely explanation of the discrepancy is that each isotope has additional strong resonances other than the single strong resonance tabulated for each $(27,1)$. For Mo ${ }^{100}$ the experiment indicates further high energy resonances at energies above those of the resolved resonances. For $\mathrm{MO}^{98}$ an additional resonance in the energy range from 70 to $200 \mathrm{ev}$ is indicated. An accidental colncidence of such a resundrce with the $\mathrm{Mo}^{95}$ resonance at $75 \mathrm{ev}$ or the Mo 97 resonance at 1.33 ev seems most likely. The presence of such a low energy resonance for $\mathrm{Mo}^{98}$ has also been indicated by experiments performed by Furr $(20)$ from the method of boron absorption in beam geometry.

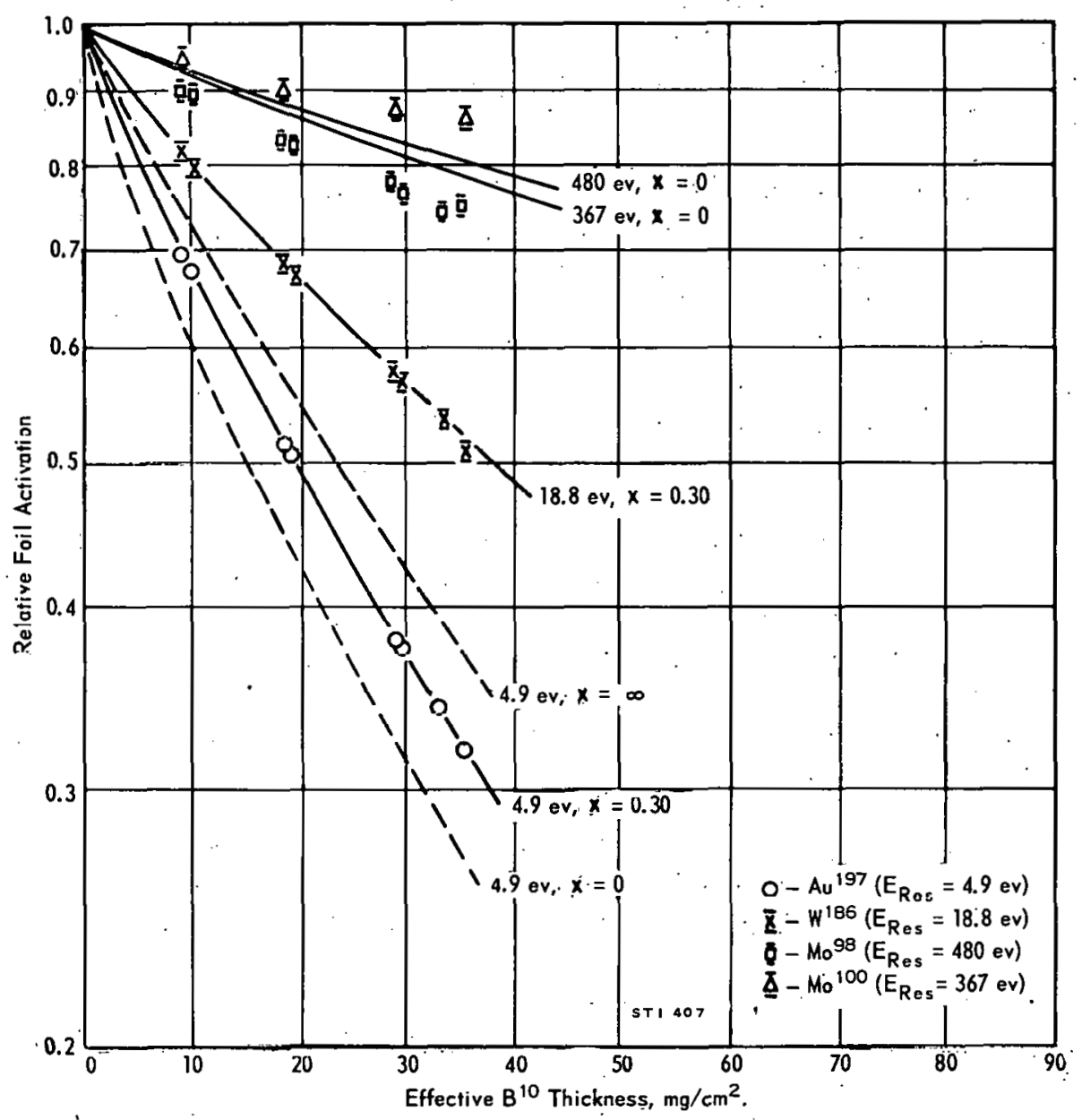

FIG. 12 SHIELDING OF RESONANCE DETECTOR FOILS BY BORON COVERS 


\section{BIBLIOGRAPHY}

1. Hughes, D. J: and R. B. Schwartz. Neutron Cross Sections. Brookhaven National Lab., Neutron Cross Section Compilation Group, Upton, N. Y. AEC Research and Development Report BNL-325, 2nd Ed., 376 pp. (July 1958); Hughes, D. J., B. A. Magurno, and M. K. Brussel. ibid., BNL-325, 2nd Ed., Suppl. 1, 132 pp. (January 1960).

2. McArthy, A. E., P. J. Persian1, B. I. Sp1nrad, and L. J. Templin. Neutron Resonance Integral and Age Data. Argonne National Laboratory, Reactor Physics Constants Center, Newsletter No. 1, (June 30, 1961).

3. Macklin, R. I. and H..S. Pomerance. "Resonance Capture Integrals". Proc. U. N. Intern. Conf. Peaceful Uses Atomic Energy, Geneva 5, 97-100 (1955).

4. Westcott, C. H. Effective Cross Section Values for WellModerated Thermal Reactor Spectra. Atomic Energy of Canada Ltd., Chalk River, Ont. Research and Development Report CRRP-960, $40 \mathrm{pp}$. (November 1960). (AECL-1101)

5. Dresner, I. Resonance Absorption in Nuclear Reactors. New York: Pergamon Press, Inc. (1960).

6. Stewart, J. C. and P. F. Zwelfel. "A Review of SelfShielding and Doppler Effects in the Absorption of Neutrons". Proc.U. N. Intern. Conf. Peaceful Uses Alumle Erergy, End, Gencva, 16, 652-56 (1958). P/637

7. Jirlow, K. and E. Johansson. "The Resonance lintegral of Gold". J. of Nucl. Energy Part A: Reactor Sclence. 11, $101-07(1960)$.

8. Martin, D. H. "Correction Factors for Cd-Covered-Foil Measurements". Nucleonics 13, No. 3, 52-3. (1955).

9. Jacks, G. M. A Study of Thermal and Resonance Neutron Flux Detectors. E. I. di. Pont de Nemours \& Co., Savannah River Laboratory, A1ken, S. C. AEC Research and Development Report DP-608, 50 pp. (August 1961).

10. Towler, O. A. and J. W. Wade. "Exponential Measurements in Heavy-Water Systems". Chem. Eng. Progr. Symposium Ser. 52, No. 19, 177-81 (1956).

11. Gavin, G. B. "Determination of the Neutron Temperature at the Center of the Thermal Test Reactor". Nuclear Sc1. and Eng. 2., 1-13 (195\%). 
12. Brown, P. S., T. J. Thompson, I. Kaplan, and A. E. Profio. Measurement of the Spatial and Energy Distribution of Thermal Neutrons in Uranium, Heavy Water Lattices. Massachusetts Institute of Technology, Department of Nuclear Engineering, Cambridge, Mass. AEC Research and Development Report NYO-10205, 210 pp. (August 1962). (MITNE-17)

13. Donahue, D. J., R. A. Bennett, and D. D. Lann1ng. "The Absorption Cross Section of Copper for Thermal Neutrons". Nuclear Sc1. and Eng. I, 184-86 (1960).

14. Dahlberg, R., K. Jirlow, and E. Johansson. "Measurements" of Some Resonance Activation Tntegrals". Reactor Scicnce ând 'l'echnology 14, 53-4 (1961).

15. Bennett, R. A. "Effective Resonance Integrals of $\mathrm{Cu}$ and Au". 20. 2G-31 uf Nuclear l'hysics Research Quarterly Report October, November, December 1959. General Electric Co., Hanford Atomics Products Operation, Richland, Wash. AFC Research and Development Report HW-63576, 76 pp. (January 1960).

16. Cabell, M. J. The Thermal'Neutron Capture Cross Section and the Resonance Capture Integral of $\mathrm{MO}^{100}$. United Kingdom Atomic Energy Authority, Atomic Energy Research Establishment, Harwell, Berks, England. Research and Development Report AERE-R-3239, 12 pp. (January 1960).

17. Cabell, M. J. The Purification and Absolute Determination of $\mathrm{Mo}^{99}$ and the Neutron Capture Cross Section of Mo ${ }^{98}$. United Kingdom Atomlc Energy Authority, Atomic Energy Research Establ1shment, Harwell, Berks, England. Research and Development Report AERE-R-3647, 17 pp. (February 1961).

18. Weinberg, A. and E. P. W1.gner. The Physical Theory of Neutron Chain Reactions. Chicago: Univ. of Chicago Press (1958).

19. Harvey, J. A., D. J. Hughes, R. S. Carter, and V. E. Pilcher. "Spacings and Neutron Widths of Nuclear Energy Levels". Phys. Rev. 99, 10-36 (1955).

20. Furr, A. K. Private Communication.

21. Lynn, J. E., F. W. K. F1rk, and M. C. Moxon. "The $2.85 \mathrm{kev}$ Neutron Resonance of Sodium". Nucl. Phys. 5, 603-14 (1958). 
22. Hardy, J., Jr., D. Klein, and G. G. Smith. "The Resonance Fission Integrals of $\mathrm{U}^{235}, \mathrm{Pu}^{239}$, and $\mathrm{Pu}^{241 "}$. Nuclear Sc1. and Eng. 2, 341-45 (1961).

23. Schm1d, L. C. and W. P. Stinson. "Neutron Spectrum in the Internal Column of the Thermal Test Reactor". Phys1cs Research Quarterly Report Apr11, May', Jurie 1961. General Electric Co., Hanford Atomics Products Operation, Richland, Wash. AEC Research and Development Report HW-70716, pp. 35-40 (July 1961).

24. Clayton, E. D. Epi-Cadmium Fission in $\mathrm{U}^{235}$. General Electric Co., Hanford Atomics Products Operation, Richland, Wash. AEC Research and Development Report AECD-4167, 29 pp. (December 1955).

25. Glendenin, L. E., K. F. Flynn, and L. M. Bollinger. "Ratio of Symmetric to Asymmetric Neutron Fission of U-235". Trans. Am. Nucl. Soc. 5, No. 1, p. 20 (1962).

26. Hellstrand, E. and G. Lundgren. "The Resonance Integral for Uranium Metal and Oxide". Nuclear Sc1. and Eng. 12, 435-36 (1962).

27. Kelber, C. N. "Resonance Integrals for Gold and Indium Folls". Nucleonics 20 , No. 8, p. 162 (1962).

28. Trubey, D. K., T. V. Blosser, and G. M. Estabrook. "Correction Factors for Foil-Activation Measurements of Neutron F'luxes in water and Graphite". Neutron Physics Division Annual Progress Report for Period Ending September 1, 1959. Oak Ridge National Laboratory, Oak Ridge, Tenn. AEC Research and Development Report ORNL-2842, 204-15 (1959).

29. Bogart, D. and D. Shook. "Self-Shielding in Tungsten Resonances Dominated by the $18.8 \mathrm{ev}$ Strongly Scattering Absorpt1ve Resonance". Trans. Am. Nucl. Soc. 3, No. 2, $461-62(1960)$.

30. Case, K. M., G. Placzek, and F. DeHoffman. Introduction to the Theory of Neutron Diffusion. U. S. Government Printing Office, Washington, D. C. (June 1953).

31. Von Dardel, G. and R. Persson. "Determination of Neutron Resonance Parameters from Measurements of the Absorption Integral: Application to the Main Resonance of Uranium238". Nature 170, 1117-18 (1952). 
32. Jahnke, E. and F. Emde. Tables of Functions w1th Formulae and Curves. New York: Dover Publications (1945).

33. Roe, G. M. The Absorption of Neutrons in Doppler Broadened Resonances. .Knolls Atomic Power Laboratory, Schenectady, N. Y. AEC Research and Development Report KAPL-1241, 85 pp. (1954).

34. Westcott, C. H. Effective Cross Section for WellModerated Thermal Reactor Spectra: Atomic Energy of Canada Ltd., Chalk River, Ont. Research and Development Report CRRP-787, 29 pp. (1958). (AECL-670) 